\title{
Drop Tests of the Redesigned 9975 Package
}

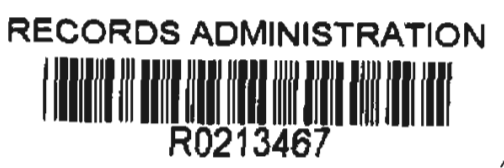

by

A. c. Smith

Westinghouse Savannah River Company

Savannah River Site

Aiken, South Carotina 29808

This paper was prepared in connection with work done under the above contract number with the U. S. Department of Energy. By acceptance of this paper, the publisher and/or recipient acknowledges the U. S. Government's right to retain a nonexclusive, royalty-free license in and to any copyright covering this paper, along with the right to reproduce and to authorize others to reproduce all or part of the copyrighted paper. 
Keywords:

9975 Shipping Package

Drop Test

Closure

Drop Tests of the Redesigned 9975 Package

June 2000

\begin{abstract}
A.C. Smith
June, 2000
\end{abstract}

SAVANNAH RIVER TECHNOLOGY CENTER, AIKEN, SC 29808 Westinghouse Savannah River Co. 
This report was prepared by Westinghouse Savannah River Company (WSRC) for the United States Department of Energy under contract DE-AC09-96SE18500 and is an account of work performed under that contract. Neither the United States, the United States Department of Energy nor WSRC, nor any of their employees, makes any warranty, express or implied, or assumes any legal liability or responsibility for the accuracy, completeness, or usefuIness of any information, apparatus, product or process disclosed herein, or represents that its use will not infringe privately owned rights.

Reference herein to any specific commercial product, process or service by trade name, mark, manufacturer, or otherwise does not necessarily constitute or imply endorsement, recommendation, or favoring or same by WSRC or by the United States Government or any agency thereof. The views and opinions of authors expressed herein do not necessarily state or reflect those of the United States Government or any agency thereof. 
Table of Contents

Summary

1.0 Background

2.0 Test Program

3.0 Test Apparatus

4.0 Drop Tests

5.0 Results

6.0 Discussion

7.0 Conclusions

8.0 References

Tables

Figures 
List of Figures

Figure 1. Test 1: Package 9975-TEST-8 rigged for the CG-Over-Corner NCT preconditioning drop.

Figure 2. Test 1: Package 9975-TEST-8 after the preconditioning drop.

Figure 3. Test 1: Package 9975-TEST-8 rigged for the $17.5^{\circ}, 30 \mathrm{ft} \mathrm{HAC}$ drop.

Figure 4. Test 1: Package 9975-TEST-8 following the HAC drop.

Figure 5. Test 1: Damage to $9975-T E S T-8$ caused by the $30 \mathrm{ft}$ drop.

Figure 6. Test 1: Damage to $9975-T E S T-8$ caused by the $30 \mathrm{ft}$ drop.

Figure 7. Test 1: Results of the Puncture Pin Test of 9975-TEST-8.

Figure 8. Test 1: Overall view of 9975-TEST-8 following the sequential NCT, HAC and Puncture Pin Tests.

Figure 9. Test 2: Package 9975-TEST-9 following the CG-Over-Corner NCT preconditioning drop.

Figure 10. Test 2: Deformation of flange of 9975 -TEST-9 caused by NCT preconditioning drop.

Figure 11. Test 2: Overall view of 9975-TEST-9 following NCT preconditioning drop.

Figure 12. Test 2: Top of 9975-TEST-9 following $30 \mathrm{ft} \mathrm{HAC} \mathrm{drop.}$

Figure 13. Test 2: Overall view of 9975-TEST-9 following $30 \mathrm{ft}$ drop.

Figure 14. Test 2: Buckled flange and deformation of drum wall caused by $30 \mathrm{ft}$ drop of 9975-TEST-9.

Figure 15. Test 2: Top view of 9975-TEST-9 following $30 \mathrm{ft}$. drop, showing buckled flange and buckling of top.

Figure 16. Test 2: 9975-TEST-9 rigged for puncture pin drop.

Figure 17. Test 2: Impact point for pin drop of 9975-TEST-9.

Figure 18. Test 3: Package 9975-TEST-10 rigged for the $17.5^{\circ}$, top down NCT preconditioning test. 
Figure 19. Test 3: 9975-TEST-10 following the NCT preconditioning drop.

Figure 20. Test 3: 9975 -TEST-10 rigged for the $10^{\circ}$, bottom down (slap-down) $30 \mathrm{ft}$ HAC drop.

Figure 21. Test 3: View of 9975-TEST-10 following the $30 \mathrm{ft} \mathrm{HAC} \mathrm{drop} \mathrm{test,} \mathrm{showing}$ the buckling of the flange and top.

Figure 22. Test 3: Overall view of 9975-TEST-10 following the $30 \mathrm{ft} \mathrm{HAC}$ drop.

Figure 23. Test 3: Buckled flange assembly and top of 9975-TEST-10 following the $30 \mathrm{ft}$ slap-down drop.

Figure 24. Test 3: Package 9975-TEST-10 rigged for CG-over-impact-point puncture pin test.

Figure 25. Test 3: Deformation of top of 9975 -TEST-10 caused by impact on the puncture pin. 


\section{Drop Tests of the Redesigned 9975 Package}

\section{Summary}

A redesigned closure for the 9975 , based on that employed on the DT-22 family of packages, has been developed. The tests reported here qualify the redesigned package with respect to the requirements of 10 CFR 71.

In order to ensure that the vessel and its closure were tested in the most challenging condition, each of the packages was subjected to a Normal Conditions of Transport (NCT) preconditioning test followed by the Hypothetical Accident Condition (HAC) $30 \mathrm{ft}$ drop and puncture pin tests. The tests demonstrated the ability of the 9975 with the redesigned closure to withstand the HAC drop test sequence.

\subsection{Background}

The results of previous testing of 9975 packages revealed that the margin against failure of the ring type closure in a HAC drop test was inadequate. In response, a redesigned closure employing a bolted flange assembly, similar to that used on the Oak Ridge DT series of packages, was adopted. To qualify the redesigned closure, a series of drop tests were performed. The tests were planned to address the factors which would be expected to challenge the closure arrangement. These included drop angle, possible motion of the contents of the package; orientation of closure bolts and influence of prior NCT damage. In recognition that results of early testing might necessitate modification of the test plan, flexibility was provided in the plan.

\subsection{Test Program}

The planned test program consisted of three sequences of drops, each consisting of a $4 \mathrm{ft}$ preconditioning drop, a $30 \mathrm{ft}$ drop and a $40 \mathrm{in}$. pin drop. The tests parameters were agreed upon among Radioactive Materials Packaging Technology (RMPT), the design authority Nuclear Material Stabilization and Storage (NMS\&S), DOE Environmental Management (EM-42) and their DOE Savannah River representatives, the Competent Authority (EM-5), and the regulatory review agency Lawrence Livermore National Laboratory (LLNL). These parameters were tabulated in SRT-RMPT-2000-00035, Rev 3 (Reference 1). The test plan allowed for specification of the orientation of the preconditioning drop for Test 2 , based on the results of Test 1 , and for specification of both the preconditioning and $30 \mathrm{ft}$ drop for Test 3 , based on the results of the preceding tests. In addition, the orientations for the impact angle and orientation for the $30 \mathrm{ft}$ drop part of Test 2 and the orientation for the preconditioning drop for Test 3 were revised in response to requests by the regulatory review team, EM-5 and LLNL. The following list provides the orientations that were tested. 
Test 1: $\quad$ Preconditioning $4 \mathrm{ft}$ drop on flange in a center of gravity (CG) over corner orientation with impact midway between vent holes.

- $30 \mathrm{ft}$ drop on flange at $17.5^{\circ}$ from horizontal with impact $90^{\circ}$ from the NCT impact point.

-40 in. pin drop with the pin striking under the flange on the first bolt to the right of the NCT impact point. Drum is upright and near vertical.

Test 2: -Preconditioning $4 \mathrm{ft}$ drop on flange in a CG-over-corner orientation with the impact orientation at a vent hole.

- $30 \mathrm{ft}$ drop on flange at $22^{\circ}$ from horizontal with impact $180^{\circ}$ from the NCT impact point.

-40 in pin drop striking the locating pin and adjacent bolts from under the flange at the transition from the flattened side of top closure to the circular section (just counter-clockwise from reference mark 8 shown in Figure 14). Drum is upright and near-vertical.

Test 3: $\quad$ Preconditioning $4 \mathrm{ft}$ drop at $17.5^{\circ}$ from horizontal in a top-down orientation with impact at a vent hole.

- $30 \mathrm{ft}$ drop at $10^{\circ}$ (from horizontal) bottom impact (slap-down) with impact $90^{\circ}$ from the NCT impact point.

-40 in pin drop striking the top of the package $4.5 \mathrm{in}$. inside the outer edge of the lid at the fish-mouthed (Figure 23) section of the flange with the drum oriented for $\mathrm{CG}$ over this impact point.

The planned program is shown in Table 1.

The objective of these tests was to investigate the performance of the drum closure assembly. Accordingly, it was not necessary to perform pre- and post-test leak tests on the containment vessels

The acceptance criterion was: After the sequential tests, total vent area greater than 1.0 sq. in. shall be evaluated to determine if thermal testing is required. This criterion was agreed upon in pre-test planning discussions among the DOE regulatory review agency, DOE-SR, NMS\&S and RMPT, and documented in the 9975 Drop Test Task Plan, Reference 1 .

\subsection{Test Apparatus}

\subsection{Test Specimens}

Several specimen 9975 packages fitted with the flanged closure were obtained from the manufacturer of the production units, for the drop tests. The axial and diametrical clearances between the internal components of the package and the drum were maximized to permit the greatest possible freedom of motion for these components. This was done to allow the maximum possible loading of the lid by these components during the impact. The width of the ligament on the flange at the cut out for the vent holes was adjusted to be the minimum allowable within the drawing tolerances, 0.29 in. With the 
exception of the flange closure assembly, the packages conformed to the reference design, Reference 2.

The drums were marked with reference points, measured from the drum seam line, as specified in the test procedures, FP-806, Reference 3. Pretest measurements of the package dimensions (axial and diametrical) were made to characterize the package.

The packages were assembled with dummy contents (representing the maximum content weight) using assembly procedures based on the requirements of the SARP (References 1 through 4). The dummy contents consisted of stainless steel round sections, with a weight of approximately $50 \mathrm{lb}$, and the standard aluminum spacer. The dummy weights were adjusted for each package to provide a total package weight close to $414 \mathrm{lb}$. This provides a $10 \mathrm{lb}$ margin above the reference weight given in the SARP.

Because this test program was investigating the drum closure, rather than the performance of the containment vessels, leak testing of the containment vessels was not required. Accordingly, the containment vessels were scrap units which would not be useable for service, but which conformed geometrically to the design drawings. The package assembly followed the standard procedures for assembly of 9975 packages, References 4 and 5 .

\subsection{Package Serial Numbers}

The serial numbers of the test packages were:

9975-TEST-8 (used for Test 1)

9975-TEST-9 (used for Test 2)

9975-TEST-10 (used for Test 3)

NOTE: Care should be taken to not confuse the serial number of the package with the test number given in Table 1.

\subsection{Drop Tests}

\subsection{Procedure and Facility}

The drop tests were performed in the 723-A high bay drop test facility in accordance with Field Procedure FP-806, Rev. 4, Drop Tests of the 9975 series Shipping Package, Reference 3. The test sequence consisted of a $4 \mathrm{ft}$ preconditioning drop, a $30 \mathrm{ft}$ drop and a 40 in. pin drop, as described in the test plan. For each drop, the package was aligned to within one degree of its nominal orientation prior to the drop. Each drop was recorded using a high-speed video camera. Following each drop, the package was measured and photographed to document the extent of damage.

The drop test surface was constructed from a 6.25 inch thick armor plate, approximately 5 feet square, anchored in a 30 inch thick reinforced concrete slab. The target slab is 
isolated from the concrete floor of the building. The target slab weighs approximately $15,600 \mathrm{lb}$., which is over 35 times the weight of the test packages (414 lb.).

\subsection{Testing}

The 9975 drop tests were performed on June 28 and 29, 2000. The testing followed the test plan, Reference 1, with the changes described in Section 2.0, above. The $4 \mathrm{ft}$ and 30 $\mathrm{ft}$ drops were performed on each of the packages, on the $28 \mathrm{th}$. The pin was then welded in place on the test pad on the morning of the $29^{\text {th }}$. The pin drop tests were performed on the afternoon of June 29. A mirror was placed near the drop pad, for the NCT and $30 \mathrm{ft}$ HAC drops, to permit recording the end view of the package in the same video view with the normal, side view.

\subsection{Results}

\subsection{Test 1 (Package Serial Number 9975-TEST-8)}

The effect of the drop testing on the package, for Test 1 , is shown in Figures 1 through 8.

\subsubsection{NCT Preconditioning Test}

The preconditioning drop was performed from an elevation of $4 \mathrm{ft}$, with the package in the CG-over-comer orientation (so that its axis was $60^{\circ}$ from horizontal, top down) at release, Figure 1. The circumferential orientation for the preconditioning drop was midway between two vent holes. The angle at impact was $59^{\circ}$, determined from the grid lines on the video image. The preconditioning drop resulted in slight, $\sim 3 / 16$ in., downward (relative to the drum) bending of the closure flange assembly over a width of approximately $5 \mathrm{in}$. at the impact point. Following initial impact, the package rotated, with the second strike being on the bottom chime with a resulting flattening over a width of about 5 in. A corresponding minor dimple was produced on the lower rolling hoop. There was no flattening of the top rolling hoop. The reduction in outside diameter of the flange closure assembly, measured through the point of contact, was negligible (diameter of 20.87 in.). The results of this drop are shown in Figure 2.

\subsubsection{Ft Drop Test}

The $30 \mathrm{ft}$ drop was performed with the package oriented so that its axis was $17.5^{\circ}$ from horizontal, top down, at release, Figure 3. The orientation of the target contact point was 90 degrees from the NCT impact point and directly above reference mark 7 (See Figure 6). The angle at impact was 15 from horizontal ${ }^{\circ}$. The drop resulted in flattening of the flange assembly at the point of contact, and associated flattening along the length of the drum. The flattened region of the upper rolling hoop was about $5.5 \mathrm{in}$. wide, the lower rolling hoop about $9.25 \mathrm{in}$. wide and the bottom chime about $10.5 \mathrm{in}$. The outside diameter of the closure flange assembly was reduced from 20.85 to $19.81 \mathrm{in}$. measured through the point of impact. The width of the flattened region of the closure flange was 7 in. The axial distance between the reference marks on the impact side remained at about 34 in. The damage was typical of comer drop damage reported for the Oak Ridge DT 
series of packages, which have a similar bolted flange closure. The flange and the corresponding ring on the top buckled between the bolts, Figure 5 . There was local buckling and folding of the drum and top in the damage region adjacent to the flange. There is no indication of failure of any weld or material adjacent to a weld. The results of this drop are shown in Figures 4 through 6.

\subsubsection{Pin Drop}

The puncture pin drop was performed from an elevation, from the pin to the strike point, of 40 in. with the package oriented so that its axis was $10^{\circ}$, from the vertical, at release, Figure 7. The target contact point for the pin was the bolts and the flange at the NCT point of impact. The drop was at the inner limit of the target zone, so that the pin struck the side of the drum and slid up to the bolts. The side of the drum (reinforced at this location by the label plate) proved strong enough to deflect the drum so that the bolts received only a glancing blow. Except for the scrape caused by the pin sliding on the drum surface, there was little additional damage to the package (Figures 7 and 8).

\subsection{Test 2 (Package Serial Number 9975-TEST-9)}

The effect of the drop testing on the package, for Test 2 , is shown in Figures 9 through 17.

\subsubsection{NCT Preconditioning Test}

The preconditioning drop was performed from an elevation of $4 \mathrm{ft}$, with the package in the CG-over-comer orientation (so that its axis was 60 from horizontal ${ }^{\circ}$, top down) at release. The circumferential orientation for the preconditioning drop was directly on the vent hole as can be seen in Figure 10. The objective was to maximize the effect of the preconditioning damage on the bolted flange closure assembly. The angle at impact was $56^{\circ}$ from horizontal. The preconditioning drop results were similar to that for Test 1 . There was a slight ( $\sim 1 / 4$ in.) downward (relative to the drum) bending of the closure flange assembly over a width of about $4.5 \mathrm{in}$. and associated flattening on the side of the drum. The flattened region of the lower rolling hoop was about 1 in. wide, and at the bottom chime about 5 in. wide. There was no flattening of the upper rolling hoop. There was negligible change in the outside diameter of the closure flange assembly (diameter was 20.85 in). The results of this drop are shown in Figures 9, 10, and 11.

\subsubsection{Ft Drop Test}

The $30 \mathrm{ft}$ drop was performed with the package oriented so that its axis was $22.5^{\circ}$, top down, at release. The circumferential orientation of the target contact point was 180 degrees from the NCT impact point, directly over the vent hole. The angle at impact was $20^{\circ}$ from horizontal. The drop resulted in bending the flange down and in, at the point of contact, and associated flattening along the length of the drum and buckling of the top. The flattened region of the upper rolling hoop was about $1.5 \mathrm{in}$, that of the lower rolling hoop was about 9 in. wide, and that of the bottom chime was about 11 in. The outside diameter of the closure flange was reduced from 20.85 to 19.87 in. measured through the 
point of contact. The width of the flattened region of the flange was 8 in. The height of the flattened side, measured from the top of the chime to the elevation of the bottom of the vertical leg of the flange, was 33.7 in., compared with a typical height 34 in. for the pre-test measurement. As for Test 1, the damage was similar to that reported for similar drops for the DT package series. The flange was pushed further in for this case than for Test 1 , with corresponding increase in buckling of the top and drum in the region surrounding the point of impact. As in the case of Test 1 , there was no indication of failure of any weld or base material adjacent to a weld. The results of this drop are shown in Figures 12 through 15.

\subsubsection{Pin Drop}

The puncture pin drop was performed from an elevation, from the pin to the strike point, of 40 in. with the package oriented so that its axis was $10^{\circ}$, from the vertical, at release, Figure 16. The target contact point for the pin was the bolts and the flange locating pin immediately counter clockwise from reference mark 8 , about $45^{\circ}$ from the HAC impact point, Figure 17. The pin struck the bolt and flange locating pin as intended, bending the flange upward slightly at this location. However, there was little additional damage to the package.

\subsection{Test 3 (Package Serial Number 9975-TEST-10)}

The effect of the drop testing on the package, for Test 3, is shown in Figures 18 through 25 .

\subsubsection{NCT Preconditioning Test}

The preconditioning drop was performed from an elevation of $4 \mathrm{ft}$, with the package oriented at $17.5^{\circ}$ from horizontal, top down, at release. The circumferential orientation for the preconditioning drop was directly on the vent hole. The objective was to maximize the effect of the preconditioning damage on the bolted flange closure assembly. The actual angle at impact was $17^{\circ}$. The low- angle preconditioning drop resulted in no detectable flattening of the closure flange assembly. There was associated flattening on the side of the drum. The flattened region of the lower rolling hoop was about $4.5 \mathrm{in}$. wide, and at the bottom chime about $7.5 \mathrm{in}$. wide. There was no flattening of the upper rolling hoop. The results of this drop are shown in Figure 19.

\subsubsection{Ft Drop Test}

The $30 \mathrm{ft}$ drop was performed with the package oriented so that its axis was $10^{\circ}$ from horizontal, bottom down, at release, to produce a slap-down impact, Figure 20. The circumferential orientation of the target contact point was 90 degrees from the NCT impact point, directly over the vent hole. The angle at impact was $5^{\circ}$. The drop resulted in bending the closure flange radially inward at the point of contact. The deformation resulted in buckling the flange downward (relative to the drum) and the matching flange ring (on the top) upward, between two adjacent bolts, creating a fish-mouth separation between the flanges of approximately $1 \mathrm{in}$., peak to peak, Figure 23. The recessed region 
of the top, immediately inside of the flange ring was deep enough to close the inner end of the fish-mouth separation, so that there was no opening into the interior of the package. In addition, the buckling of the top folded the top surface downward so that the surface of the top at the bottom of the buckle was 1.5 in below the top of the fish mouth section at the ID of the flange ring. The flattened region of the closure flange assembly was approximately 7.5 in. wide. The outside diameter of the closure flange was reduced from 20.85 to 19.87 in. measured through the point of contact. The impact also caused flattening along the length of the drum. The flattened region of the upper rolling hoop was about 5 in., that of the lower rolling hoop was about $8.5 \mathrm{in}$. wide, and that of the bottom chime was about 9 in. The axial distance from the top of the chime to the bottom of the flange, on the impact side, was $34.2 \mathrm{in}$., compared with a typical height $34 \mathrm{in}$. for the pre-test measurement. As was the case in Tests 1 and 2, the damage was similar to that reported for similar drops for the DT package series. As in the previous tests, there was no indication of failure of any weld or base material adjacent to a weld. The results of this drop are shown in Figures 21 through 23.

\subsubsection{Pin Drop}

The puncture pin drop was performed from an elevation, from the pin to the strike point, of $40 \mathrm{in}$. with the package oriented so that its center of gravity was over the target impact point, Figure 24. (The axis was $67^{\circ}$ from the vertical, at release.) The target contact point for the pin was 4.5 in radially inward from the buckle in the flange ring caused by the $30 \mathrm{ft}$ drop. The pin struck at the target point, flattening the buckled metal of the top and producing a half round depression in the top. There was evidence of scraping along one side of the depression. Following the initial impact, the package bounced and struck a second time, producing a minor dent and scrape. The second contact caused the package to rotate, so that is was at a low angle when it struck the floor. To achieve the desired orientation for the pin strike, the package was elevated to $40 \mathrm{in}$. above the puncture pin, which is more than 40 in. tall. As a result, the package experienced an additional impact from a height of over $6.5 \mathrm{ft}$. This resulted in further flattening of the side of the package, in the sector between the preconditioning drop damage and the thirty foot drop damage. The width of this flattened area was typically around $7 \mathrm{in}$. The results of this drop are shown in Figure 25.

\subsection{Discussion}

The objective of the test was to demonstrate that the 9975 bolted flange closure assembly provided adequate margin against loss of the top from the package during the $\mathrm{HAC}$ sequential tests. An acceptance criterion of total resulting vent area less than 1 sq-in. was agreed upon, Reference 1 .

The top remained securely attached throughout all of the tests. The damage to the closure flange assembly consisted of buckling of the flange ring and associated buckling of the adjacent drum and top. In no case was an opening into the package created by the damage. The fish-mouth separation of the flange assembly in Test 3 was confined to the flange ring. Because of the vertical section of the top, immediately inside of the flange 
ring, the fish-mouth separation did not result in an opening into the package. The associated buckling of the top increased the overlap between the top material and the drum wall, providing additional margin against formation of an opening.

The subsequent pin drops showed that the bolted flange closure assembly was easily able to withstand the additional, focused impact of the puncture pin.

The results of the tests confirmed that the welds specified for the design were fully able to withstand the impact and deformations caused by the sequential tests. There were no indications of failure of any weld or of the base material adjacent to a weld in any of the tests. In addition, there was no indication of cracking or other failure of the ligaments at the cut-out sections of the flange as a result of the sequential tests.

In the absence of any opening into the interior of the package, the ability of the package to withstand a subsequent regulatory fire test is not in question. Previous testing has shown that, in the absence of openings into the package, the 9975 is able to withstand the regulatory $\mathrm{HAC}$ fire.

\subsection{Conclusions}

These tests clearly demonstrated that the bolted flange closure design employed on the revised 9975 is easily able to retain the top during the regulatory test sequence.

The welds and other structural aspects of the bolted flange closure design are adequate for their function.

In addition, since the deformation caused by the sequential tests does not create an opening into the package, a HAC thermal test is not required.

\subsection{References:}

1. "Task Plan Transmittal for Drop Testing the Redesigned 9975 Package Closure", M. A. Ebra, SRT-EDS-2000-00021, June 23, 2000.

2. "Safety Analysis Report - Packages, 9965, 9968, 9972 - 9975 Packages", WSRCSA-7, Rev. 5, February 1998.

3. "Drop Tests of the 9975 Series Shipping Package", FP-806, Rev. 4, June 28, 2000.

4. "Loading and Post Test Procedure for the Primary Containment Vessel Tests of the 9975 Shipping Container", FP-804, Rev. 3, June 6, 2000.

5. "Procedure for the Final Assembly of the 9975 Shipping Container", FP-805, Rev. 2, June 26, 2000. 
Table 1. Drop Test for Redesigned 9975 Closure

\begin{tabular}{|c|c|c|c|}
\hline \multicolumn{4}{|c|}{ Test Matrix ${ }^{a}$} \\
\hline Test No. & 1 & 2 & 3 \\
\hline $\begin{array}{l}30-\mathrm{ft} \text { HAC drop impact } \\
\text { angle }\end{array}$ & $17.5 \pm 2.5^{\circ}$ & $22.5 \pm 2.5^{\circ} *$ & $10 \pm 5^{\circ}$ Slap-down \\
\hline $\begin{array}{l}\text { 4-ft NCT drop impact } \\
\text { angle }\end{array}$ & $\begin{array}{l}\text { CG over corner } \\
\left(60 \pm 5^{\circ} \text { top down }\right)\end{array}$ & $\begin{array}{l}\text { CG over corner } \\
\left(60 \pm 5^{\circ} \text { top down }\right)\end{array}$ & $17.5 \pm 5^{\circ}$ top down \\
\hline $\begin{array}{l}\text { 30-ft HAC drop } \\
\text { orientation }\end{array}$ & $\begin{array}{l}90+5^{\circ} \text { from NCT } \\
\text { impact point } \\
\text { (Midway between } \\
\text { vent holes) }\end{array}$ & $\begin{array}{l}180 \pm 5^{\circ} \text { from NCT } \\
\text { impact point (at } \\
\text { vent hole)* }\end{array}$ & $\begin{array}{c}\mathrm{TBD}^{\mathrm{e}} \\
90^{\circ} \text { from } \mathrm{NCT} \\
\text { impact point } \\
\text { (between bolts) }\end{array}$ \\
\hline $\begin{array}{l}\text { 4-ft NCT drop } \\
\text { orientation }\end{array}$ & $\begin{array}{l}\text { Midway between } \\
\text { vent holes }\end{array}$ & $\begin{array}{c}\mathrm{TBD}^{\mathrm{e}} \\
\text { On vent hole.* }\end{array}$ & $\begin{array}{c}\text { TBD } \\
\text { On vent hole.* }\end{array}$ \\
\hline Puncture $^{b}$ & $\begin{array}{l}\text { Pin Strike TBD } \\
\text { Bottom of flange } \\
\text { at NCT impact }\end{array}$ & $\begin{array}{l}\text { Pin Strike TBD } \\
\text { Bottom of flange } \\
45^{\circ} \text { from HAC }\end{array}$ & $\begin{array}{l}\text { Pin Strike TBD } \\
\text { On top, } 4.5 \text { in. inside } \\
\text { of HAC impact }\end{array}$ \\
\hline $\begin{array}{l}\text { Diametral Gaps } \\
\text { (inches) }\end{array}$ & $\begin{array}{l}\mathrm{OD}(\mathrm{C}): 0.22+0.05 \\
\mathrm{OD}(\mathrm{L}): 0.22 \pm 0.05\end{array}$ & $\begin{array}{l}\text { OD(C):0.22+0.05 } \\
\text { OD(L): } 0.22 \pm 0.05\end{array}$ & $\begin{array}{l}\mathrm{OD}(\mathrm{C}): 0.22+0.05 \\
\mathrm{OD}(\mathrm{L}): 0.22 \pm 0.05\end{array}$ \\
\hline Package weight (Ibs) & $414 \pm 5 \mathrm{lbs}$ & $414 \pm 5 \mathrm{lbs}$ & $414 \pm 5 \mathrm{lbs}$ \\
\hline Temperature & Ambient & Ambient & Ambient \\
\hline Drum diameter & $\begin{array}{c}9975 \\
\text { (nominal) }\end{array}$ & $\begin{array}{c}9975 \\
\text { (nominal) }\end{array}$ & $\begin{array}{c}9975 \\
\text { (nominal) }\end{array}$ \\
\hline $\begin{array}{l}\text { Stack Gap } \\
\text { (inches) }\end{array}$ & $0.19+0.25,-0.06$ & $0.19+0.25,-0.06$ & $0.19+0.25,-0.06$ \\
\hline
\end{tabular}

* Conditions changed during testing are shown in Bold.

a. After sequential tests the following criterion applies: Total vent area greater than 1.0 square inches will require evaluation to determine whether thermal testing for the new closure design is required.

b. Pin strike location will be that determined by the test leader, with concurrence of regulatory and design authority personnel present at tests, to be most challenging to retention of the lid.

c. The "OD (C)" refers to the diametral gap between the OD of the Celotex" insulation bottom subassembly and the ID of the drum wall. "OD (L)" refers to the diametral gap between the $\mathrm{OD}$ of the lead and the ID of the Celotex insulation.

d. Top of Celotex and air shield assembly to inside of top of drum.

e. TBD's will be approved by WSRC, DOE-SR, and EM-5. LLNL will advise EM-5, DOE-SR has approval authority for EM-42.

f. The tested packages will have a conservative flange thickness in the coped-out area near the caplug hole. The test packages received from the vendor to be drop tested will have coped-out sections cut and rewelded by a certified welder to the minimum specified in the drawings. 


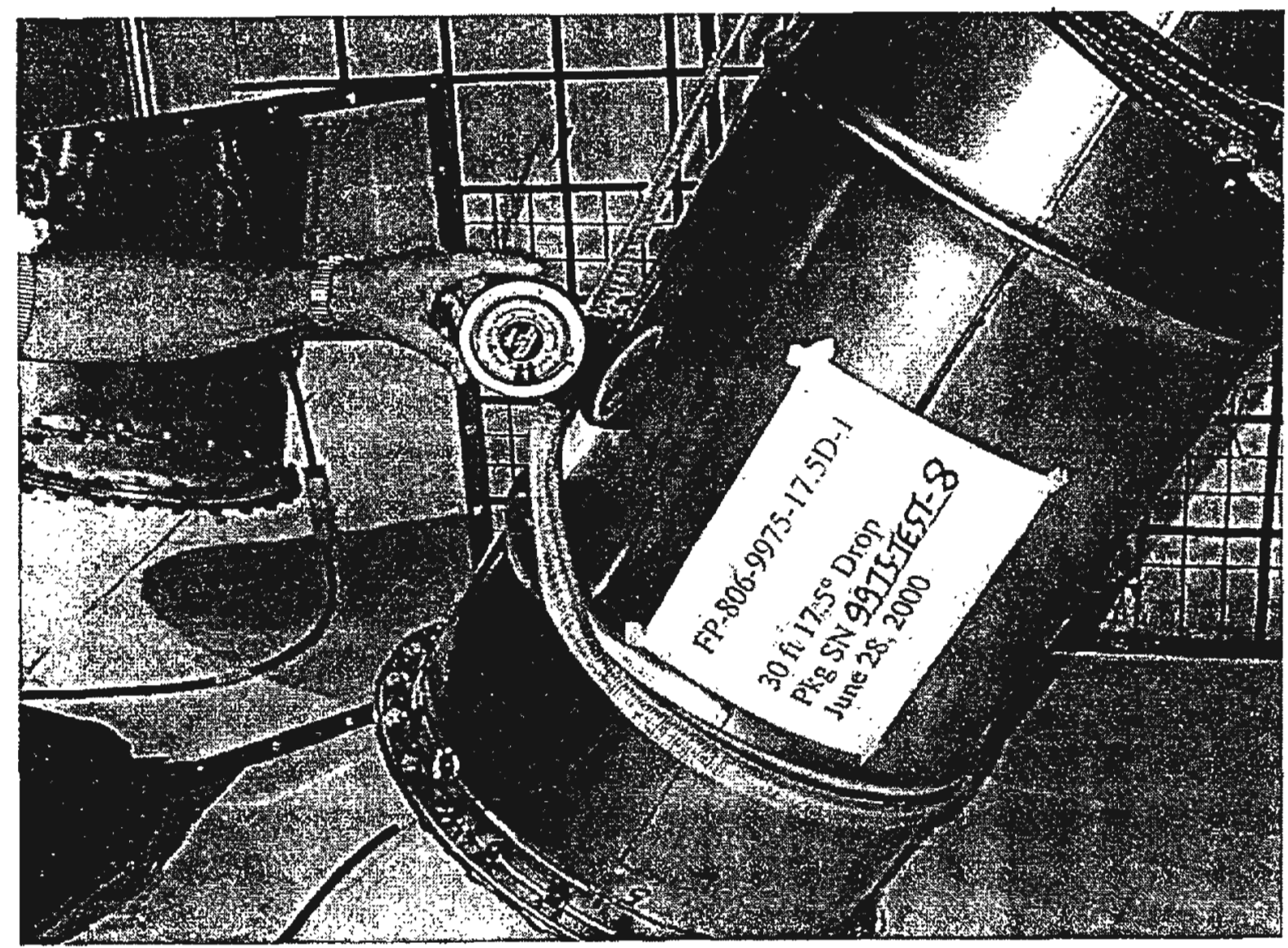

Figure 1. Test 1: Package 9975-TEST-8 rigged for the CG-Over-Corner NCT preconditioning drop. 


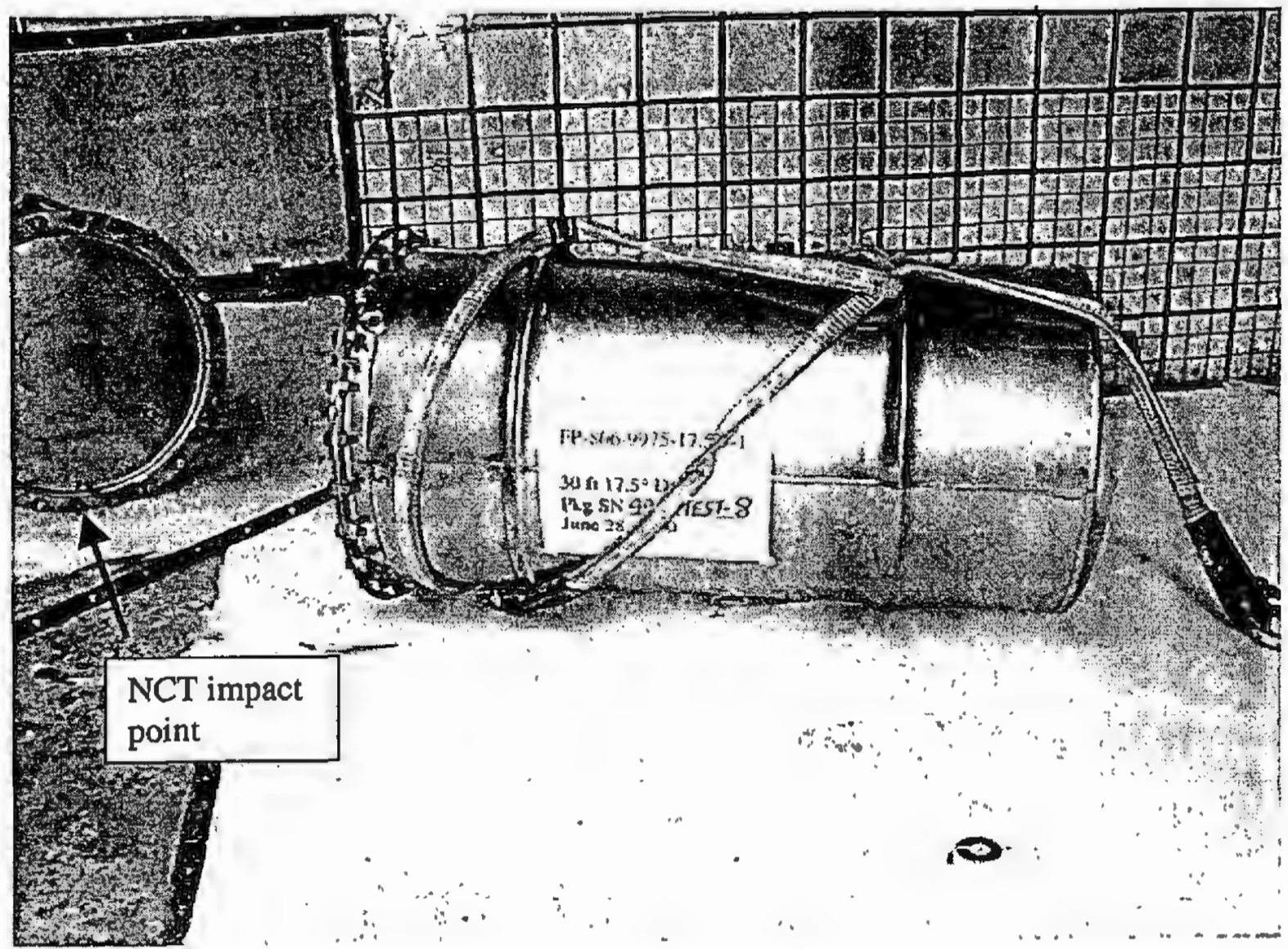

Figure 2. Test 1: Package 9975-TEST-8 after the preconditioning drop. The impact bent the flange downward a small amount $(-3 / 16$ in.) and caused some minor, local buckling of the wall of the drum. 


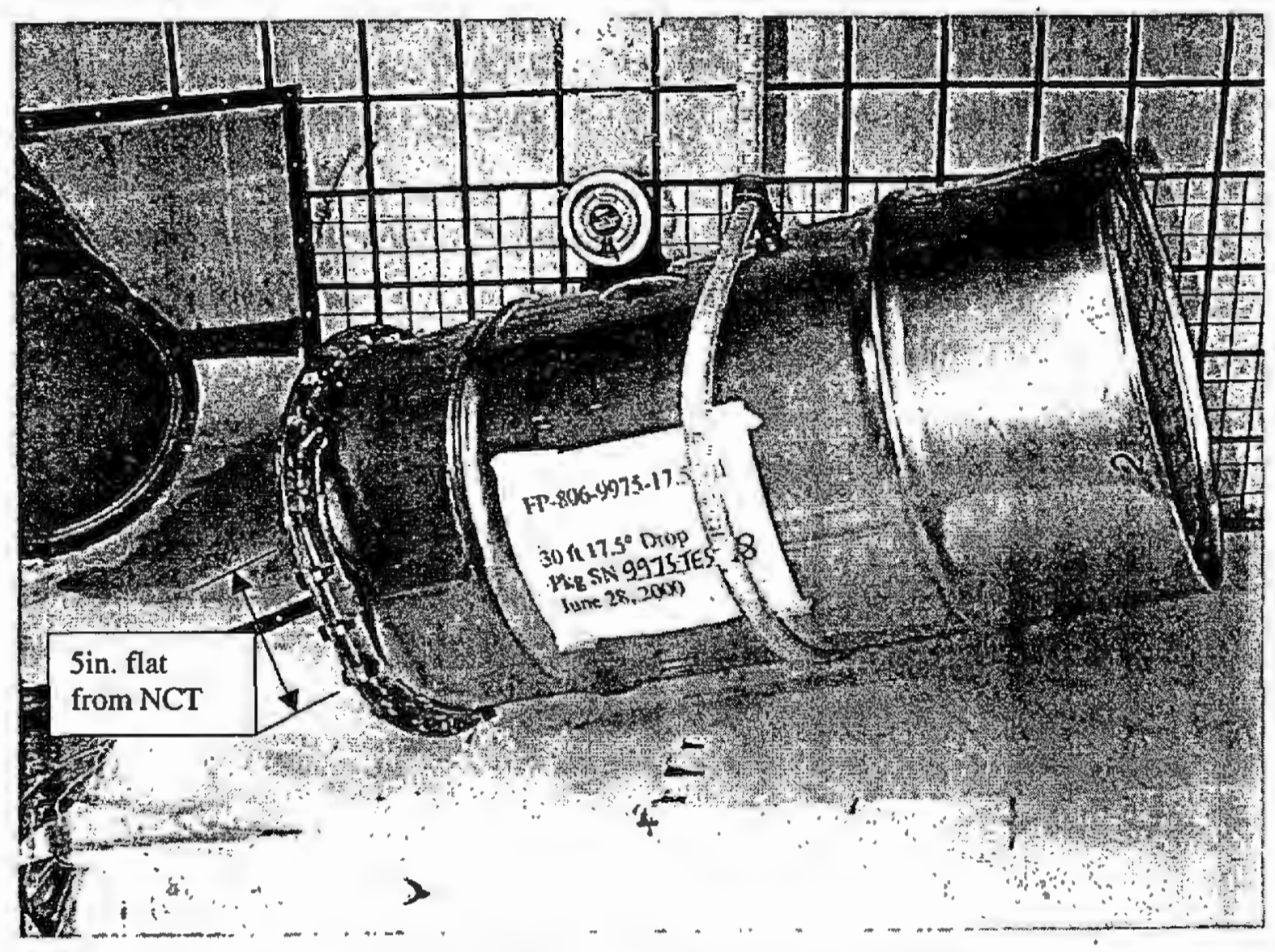

Figure 3. Test 1: Package 9975-TEST-8 rigged for the $17.5^{\circ}, 30 \mathrm{ft}$ HAC drop. 


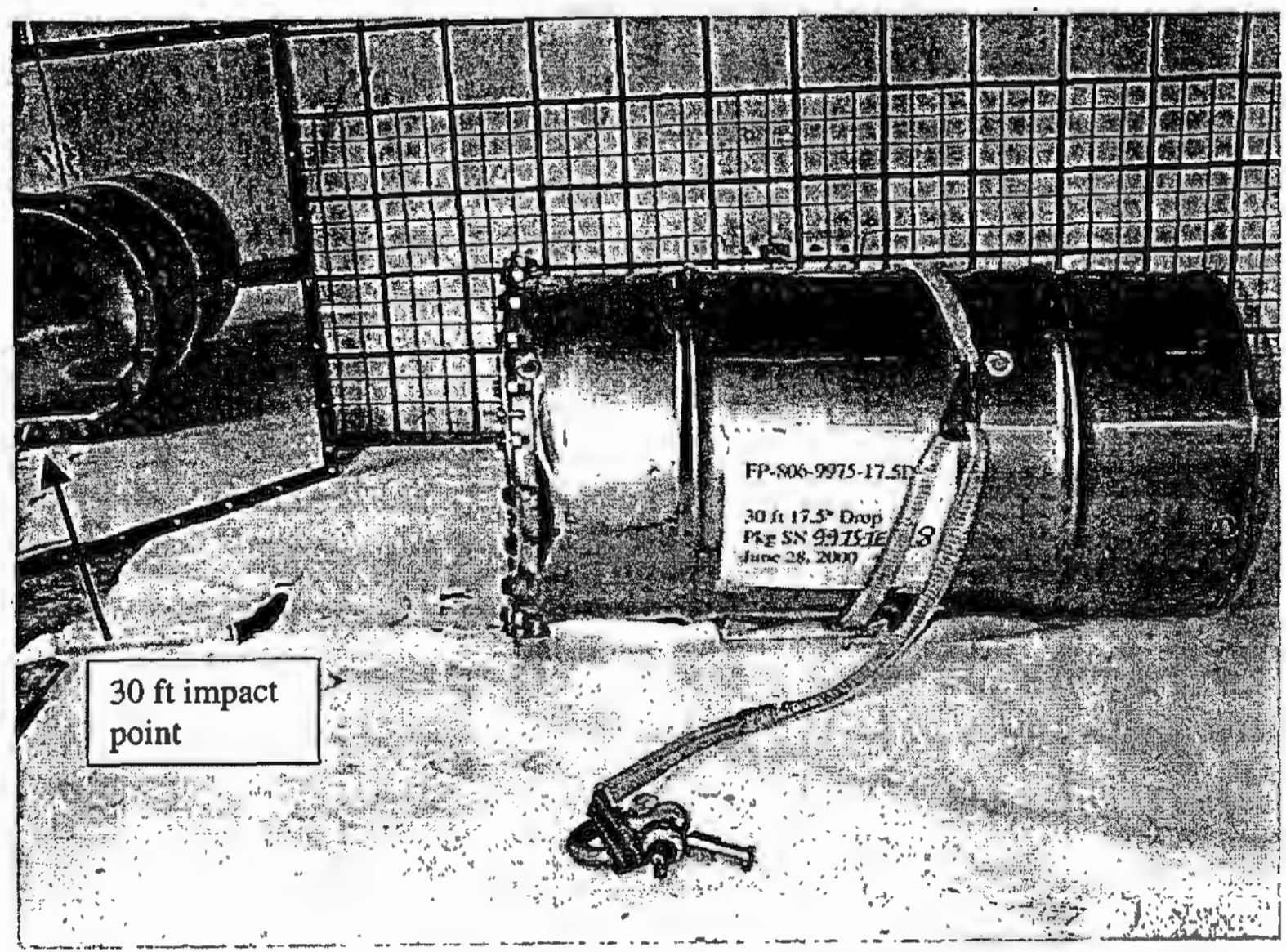

Figure 4. Test 1: Package 9975-TEST-8 following the HAC drop. The flange ring was flattened in the region of the point of contact. 


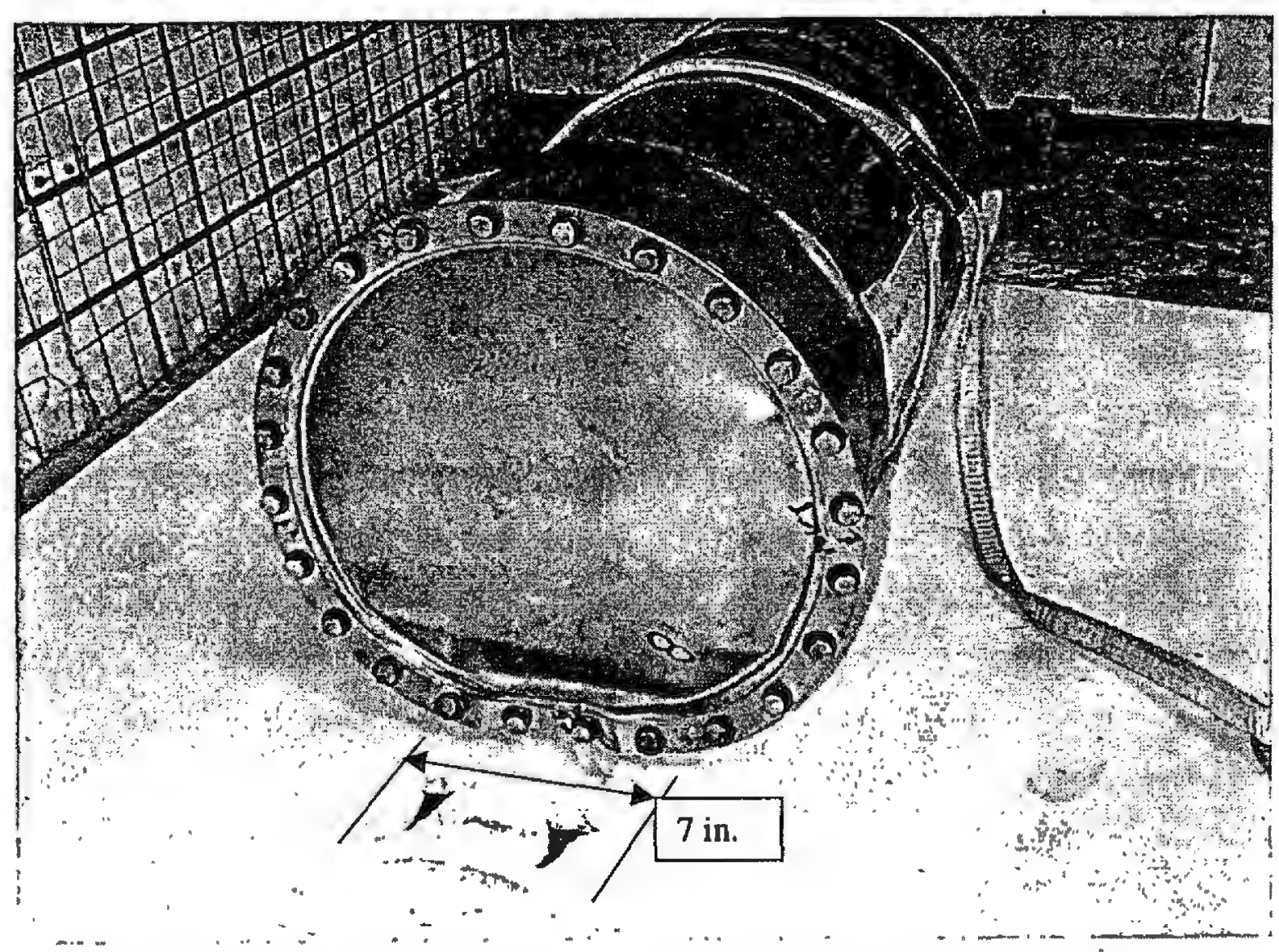

Figure 5. Test 1: Damage to $9975-T E S T-8$ caused by the $30 \mathrm{ft}$ drop. The flange closure was flattened in the region of the point of impact, with associated buckling of the flange and the top of the package. 


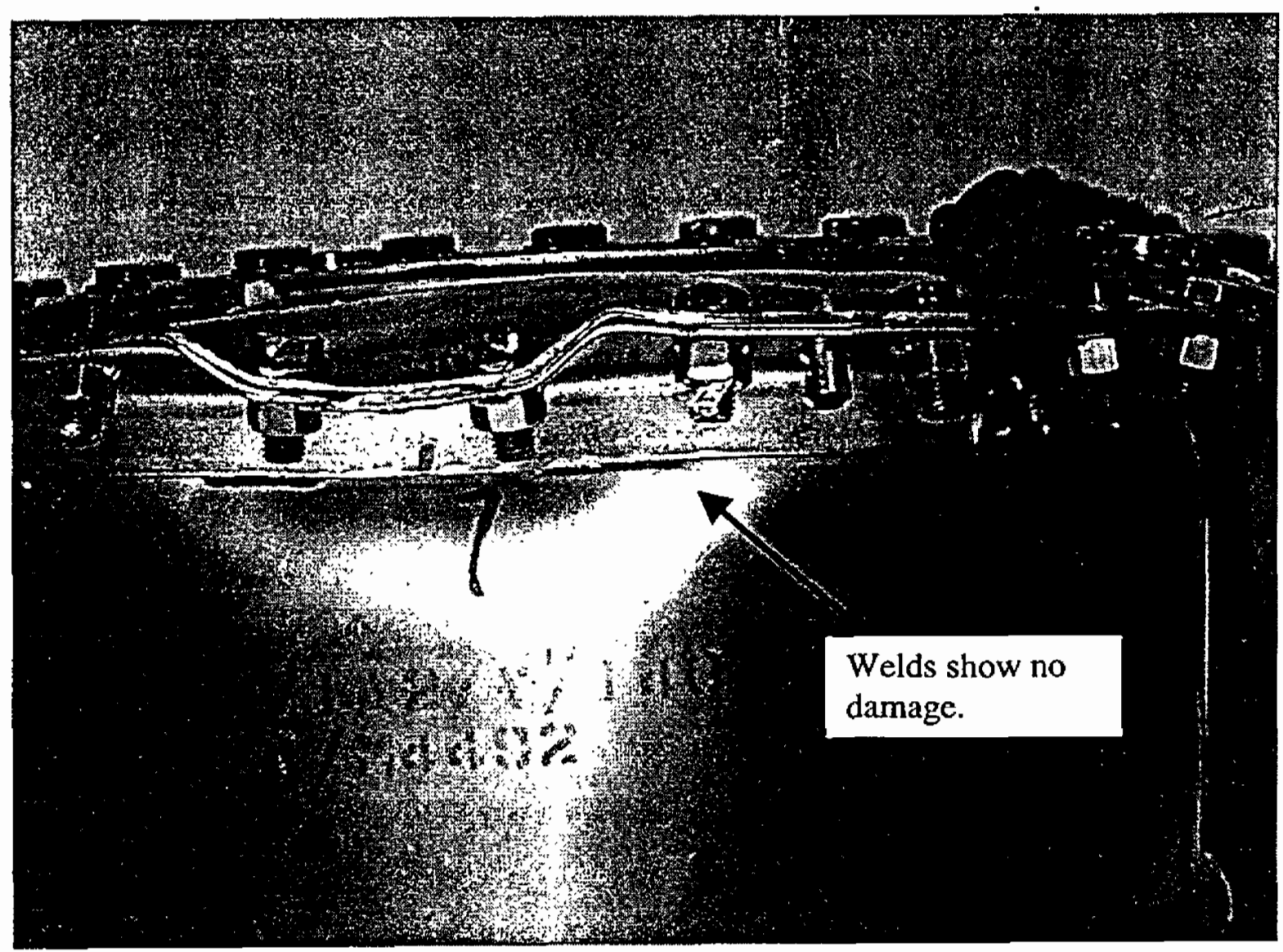

Figure 6. Test 1: Damage to $9975-\mathrm{TEST}-8$ caused by the $30 \mathrm{ft}$ drop. This view shows buckling of the flange assembly and adjacent sides of the drum. 


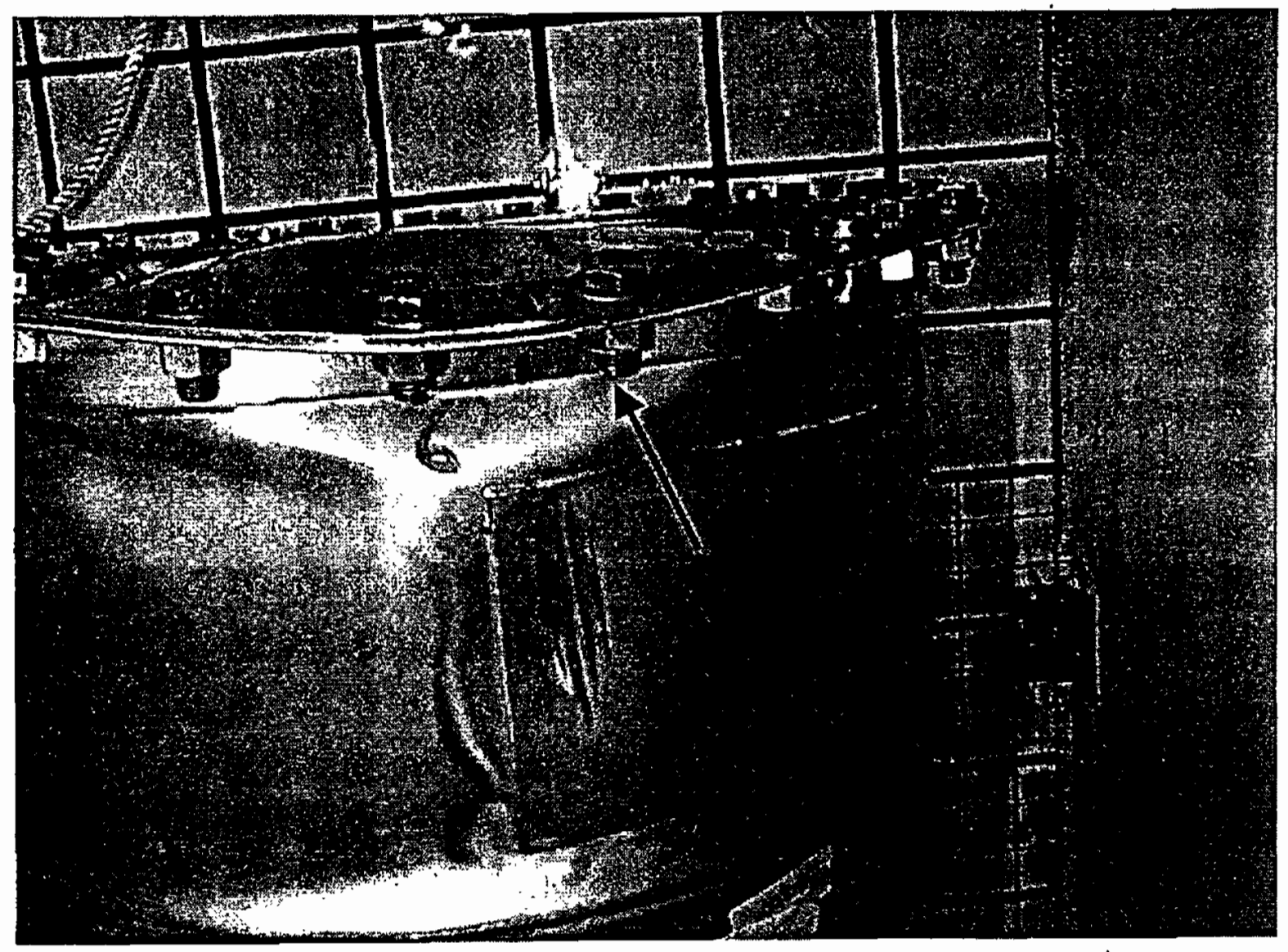

Figure 7. Test 1: Results of the Puncture Pin Test of 9975-TEST-8. The pin scraped the side of the package and glanced off of the bolt to the right of reference mark 6 . The arrow indicates the paint mark left on the bolt by the puncture pin. 


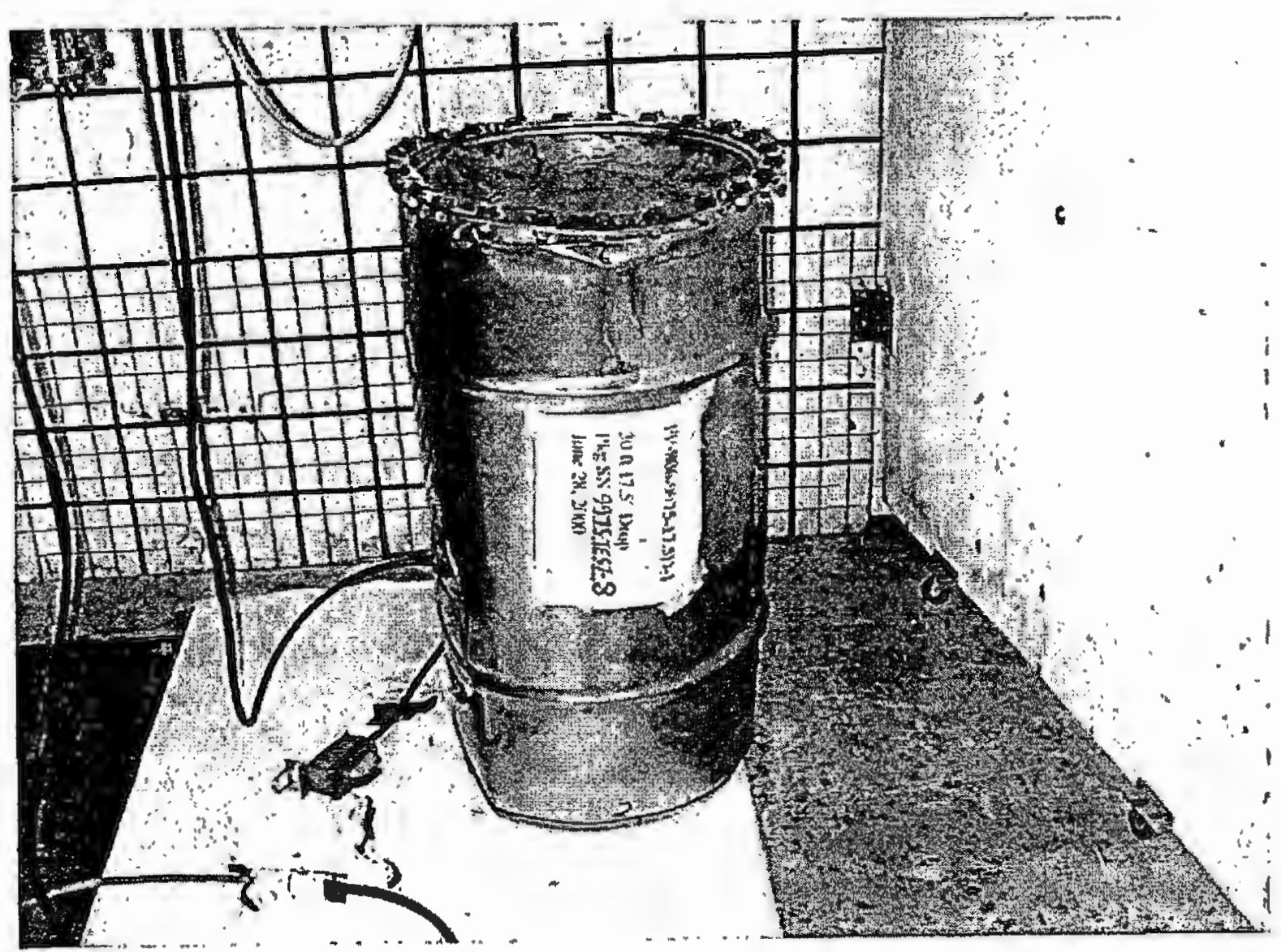

Figure 8. Test 1: Overall view of 9975-TEST-8 following the sequential NCT, HAC and Puncture Pin Tests. 


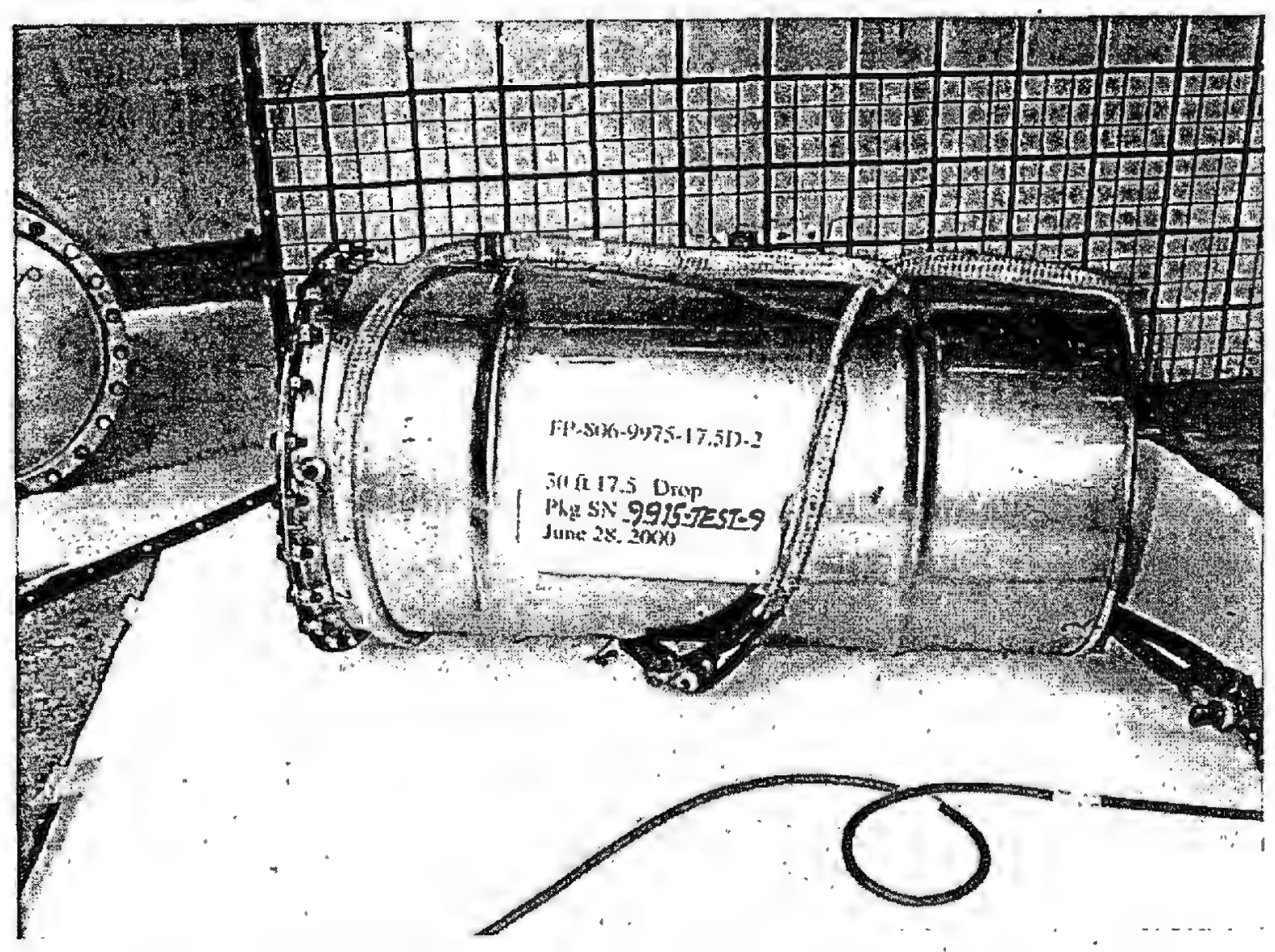

Figure 9. Test 2: Package 9975-TEST-9 following the CG-Over-Corner NCT preconditioning drop. 

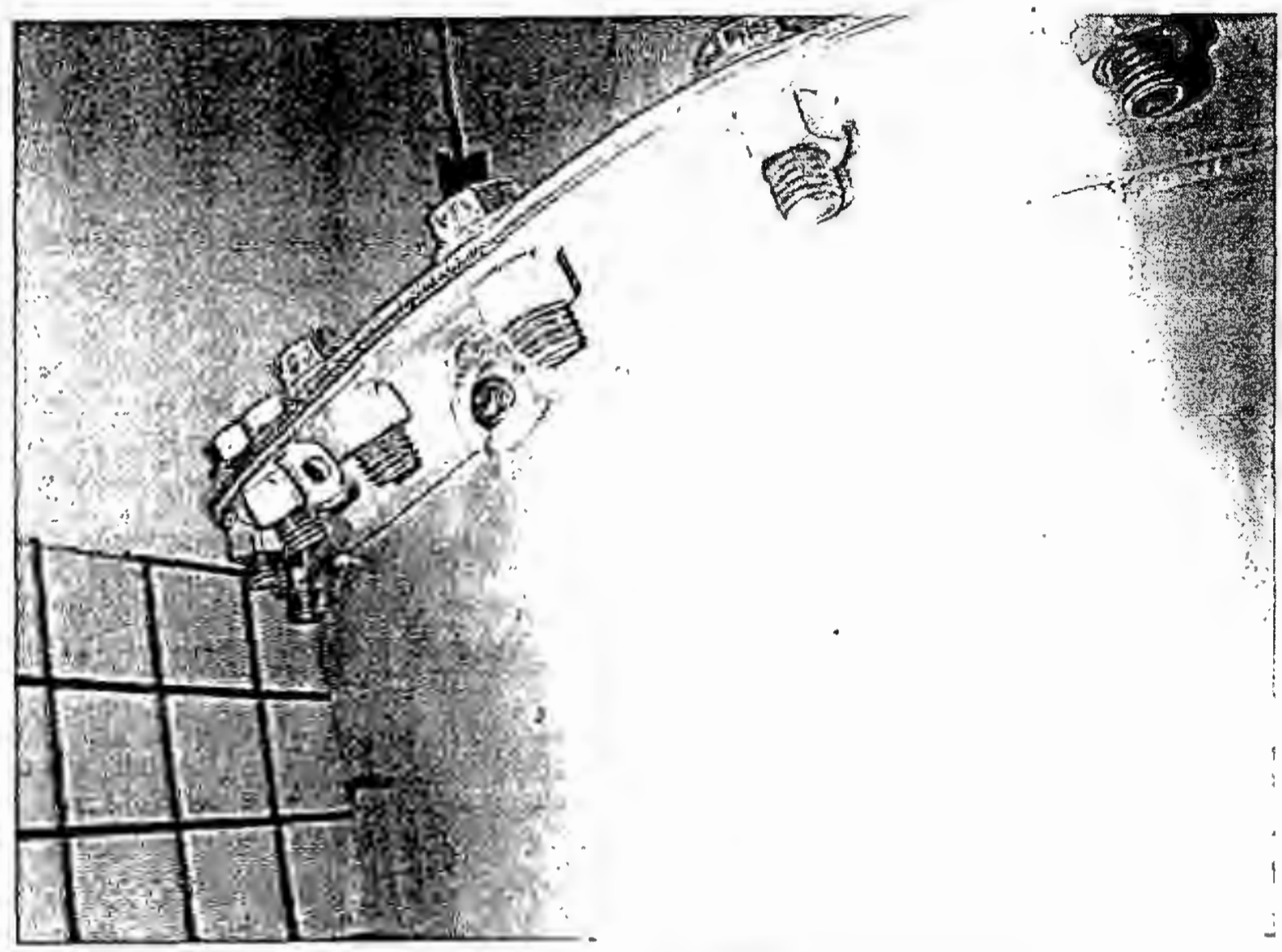

Figure 10. Test 2: Deformation of flange of 9975-TEST-9 caused by NCT preconditioning drop. Impact was directly at vent hole. 


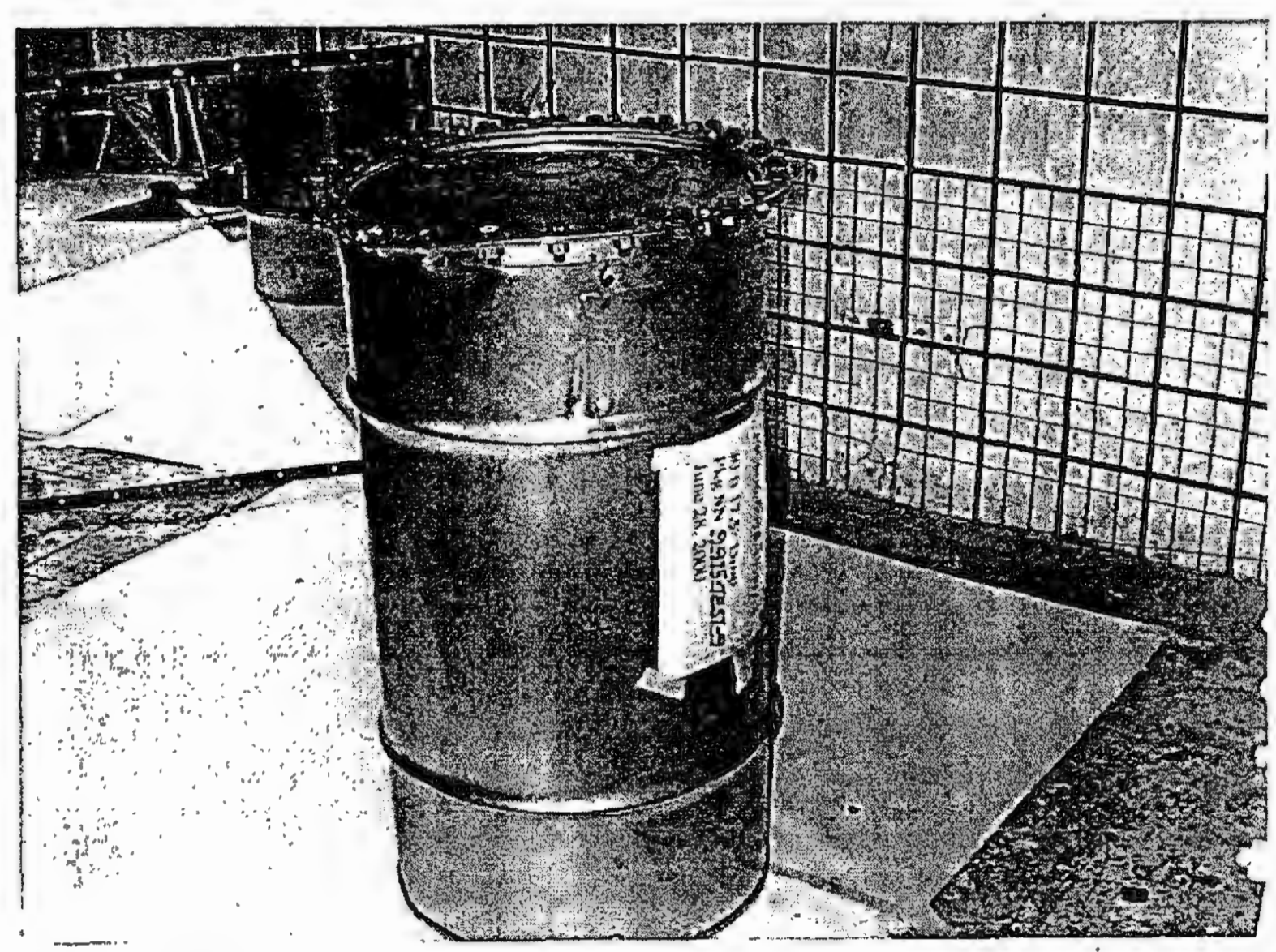

Figure 11. Test 2: Overall view of 9975-TEST-9 following NCT preconditioning drop. 


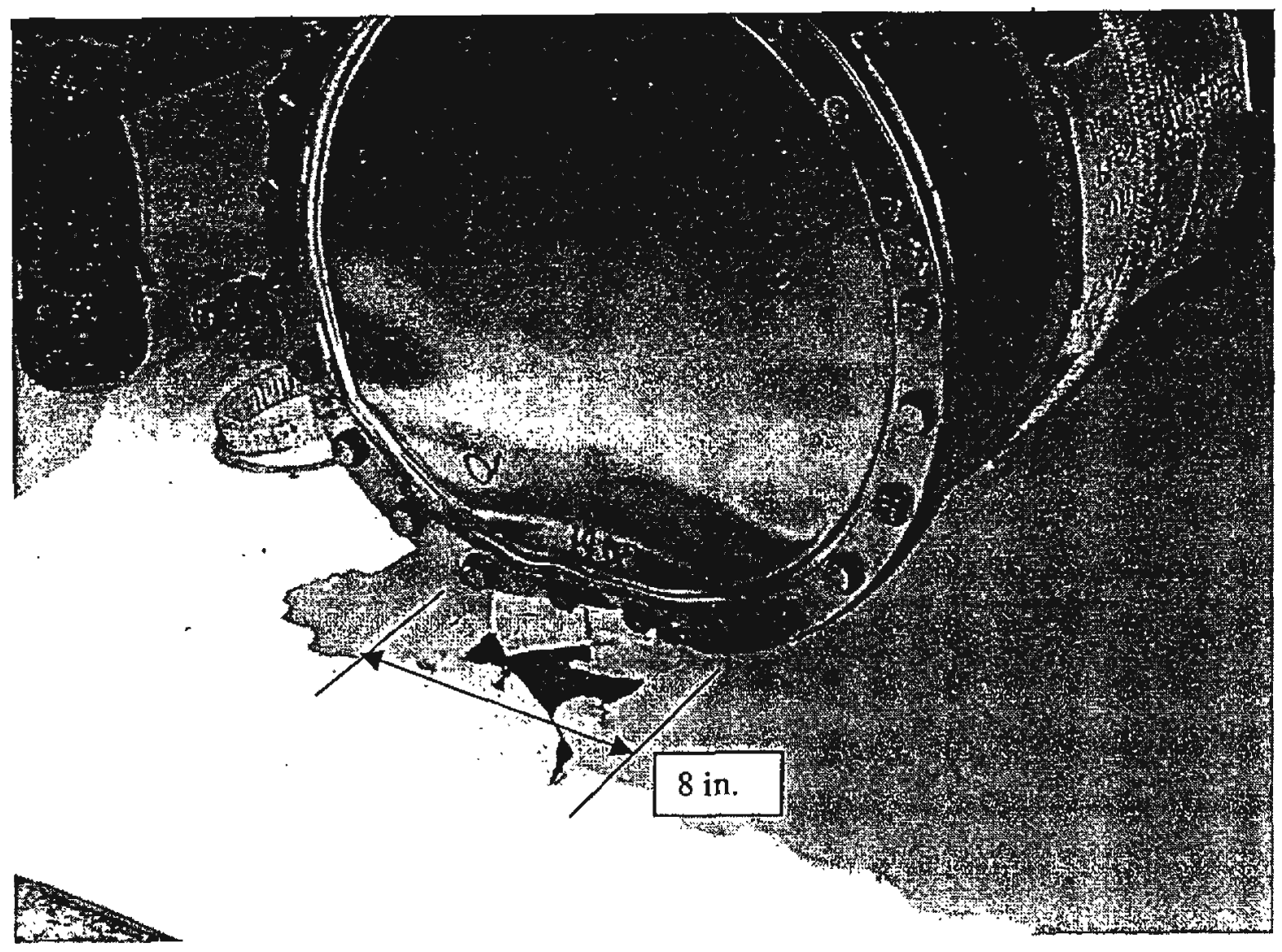

Figure 12. Test 2: Top of 9975-TEST-9 following $30 \mathrm{ft} \mathrm{HAC} \mathrm{drop.}$ 


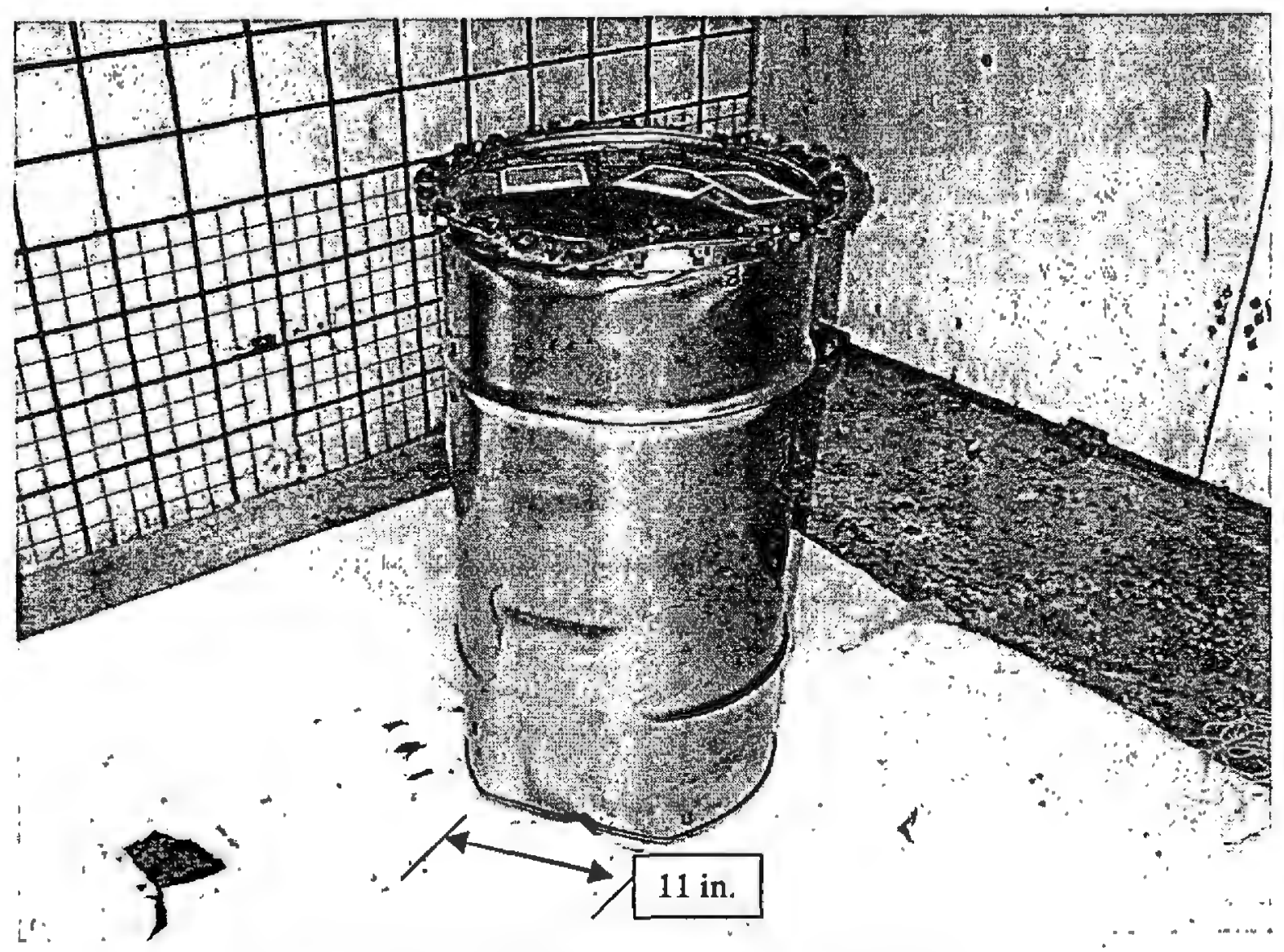

Figure 13. Test 2: Overall view of 9975-TEST-9 following $30 \mathrm{ft}$ drop. 


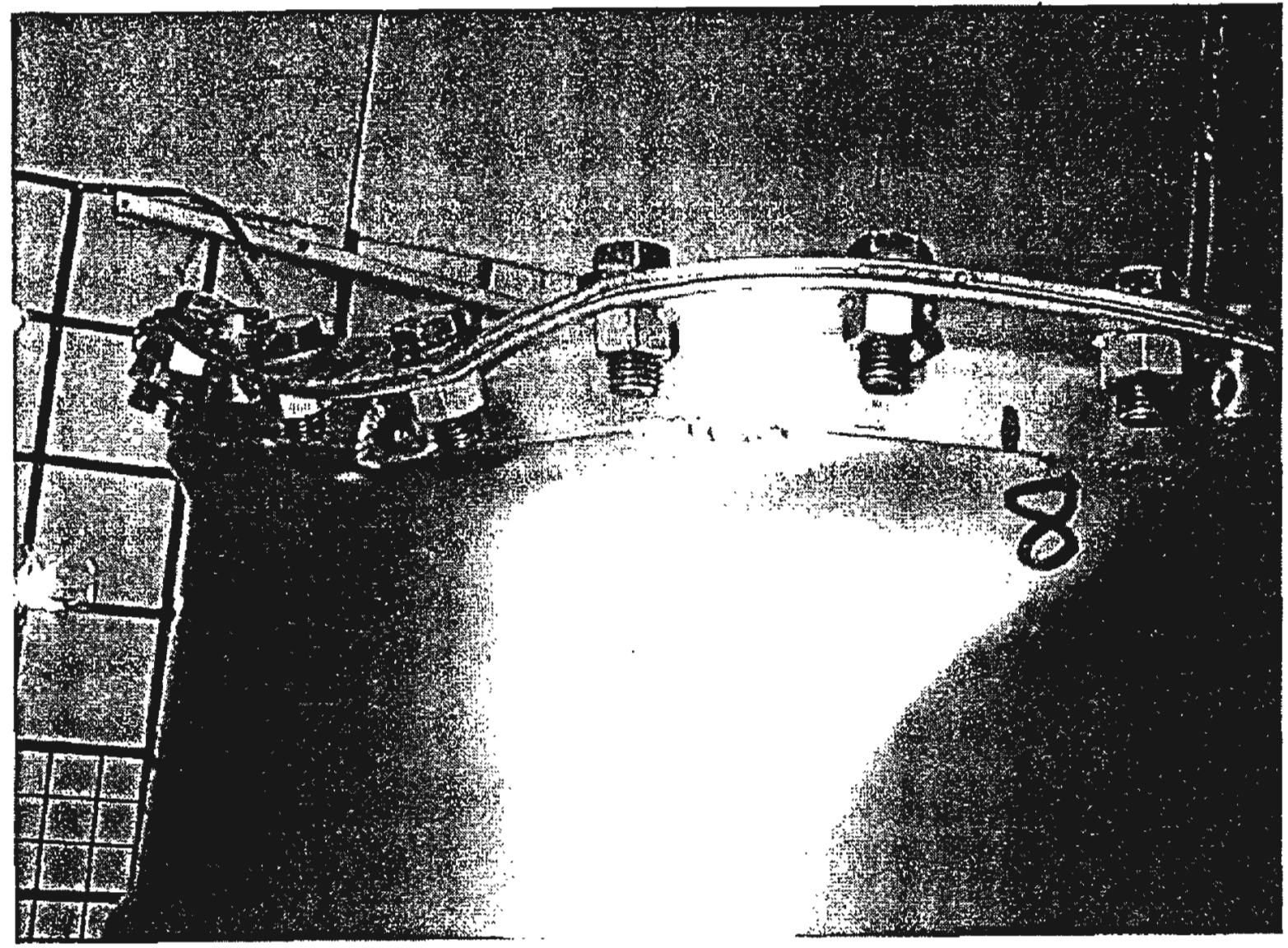

Figure 14. Test 2: Buckled flange and deformation of drum wall caused by $30 \mathrm{ft}$ drop of 9975-TEST-9. 


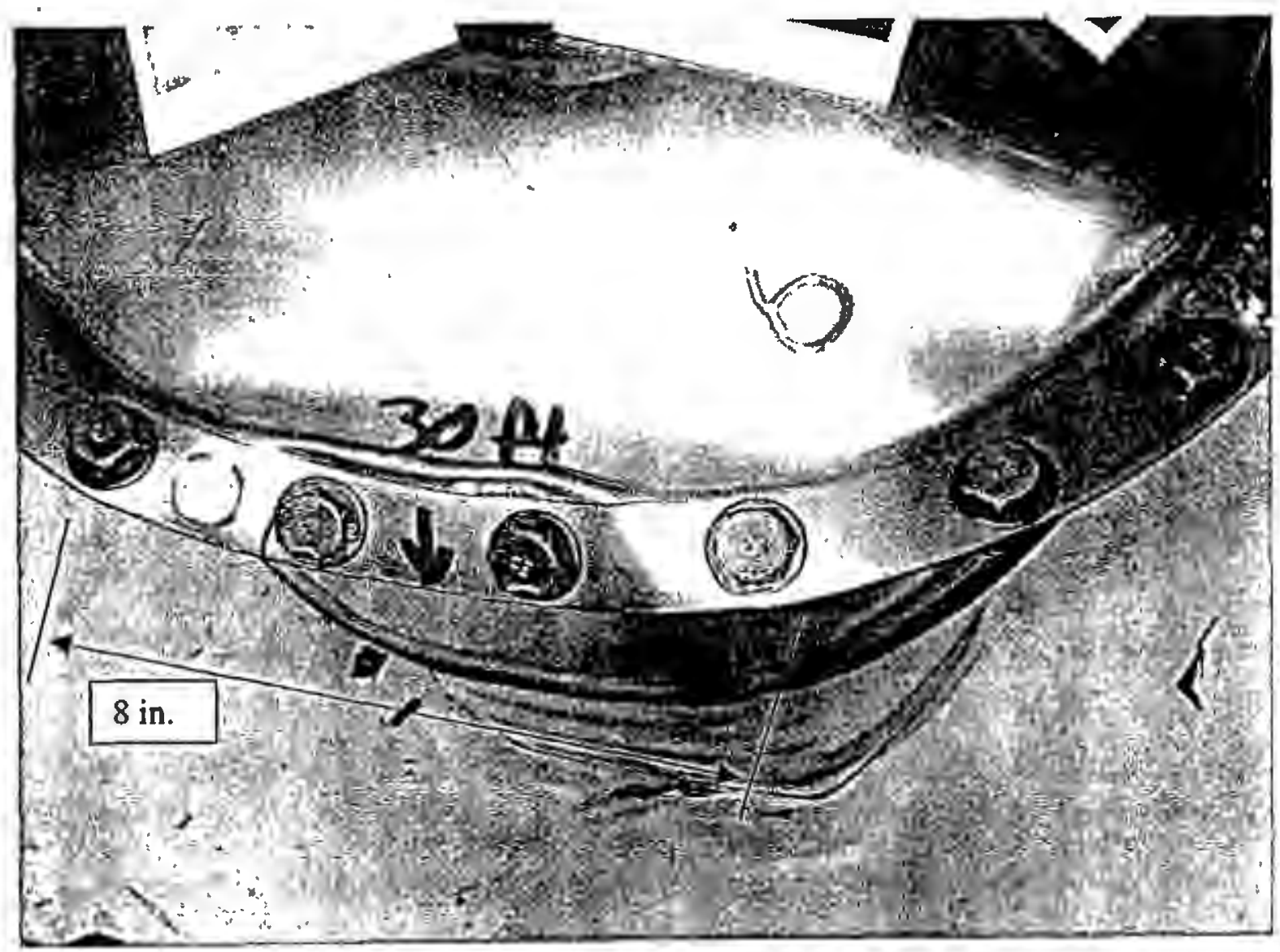

Figure 15. Test 2: Top view of 9975 -TEST-9 following $30 \mathrm{ft}$ drop, showing buckled flange and buckling of top. 


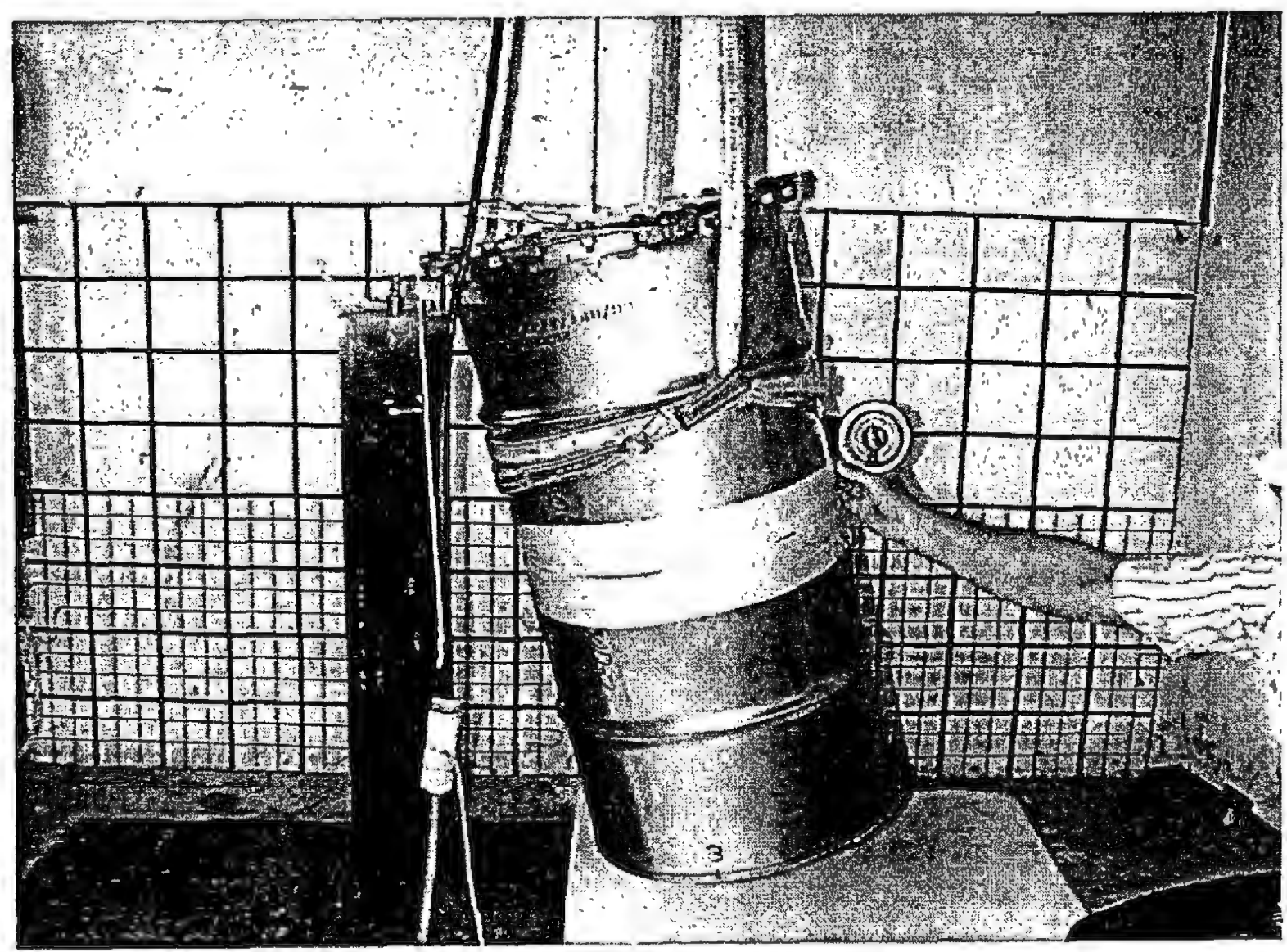

Figure 16. Test 2: 9975-TEST-9 rigged for puncture pin drop. 


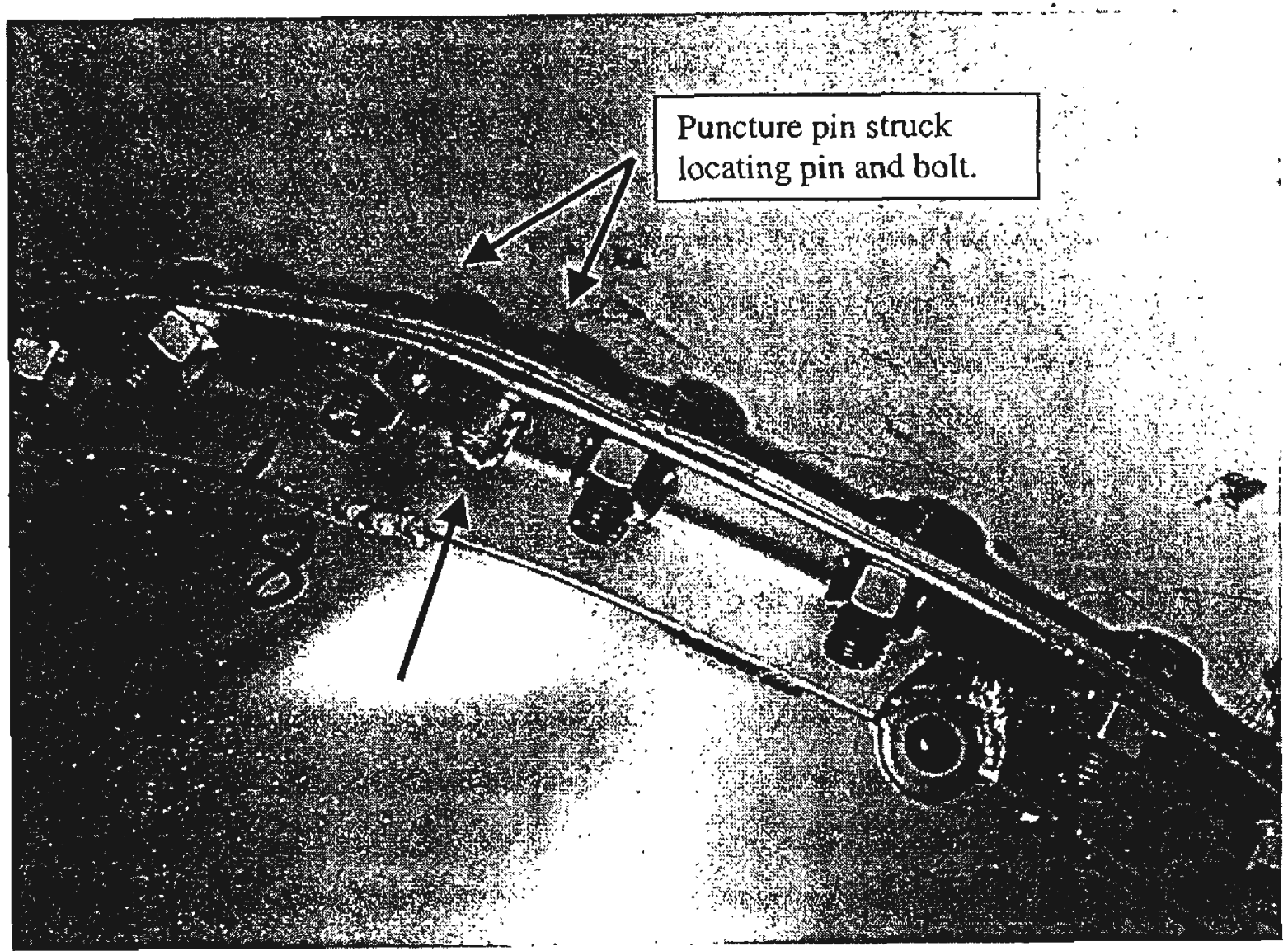

Figure 17. Test 2: Impact point for pin drop of 9975-TEST-9. The arrow indicates the paint mark on the flange locating pin caused by impact with the painted top of the puncture pin. 


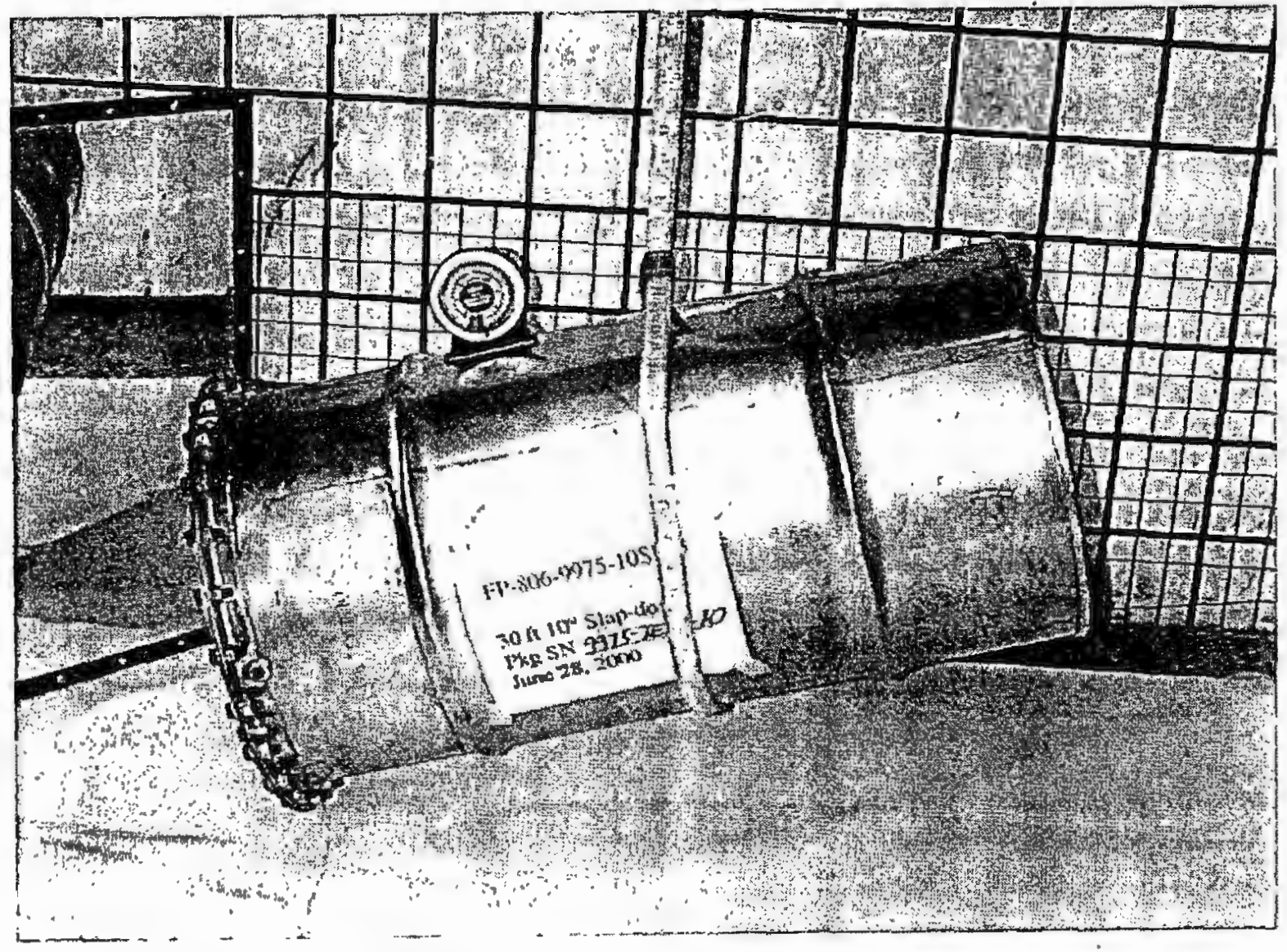

Figure 18. Test 3: Package $9975-T E S T-10$ rigged for the $17.5^{\circ}$, top down NCT preconditioning test. 


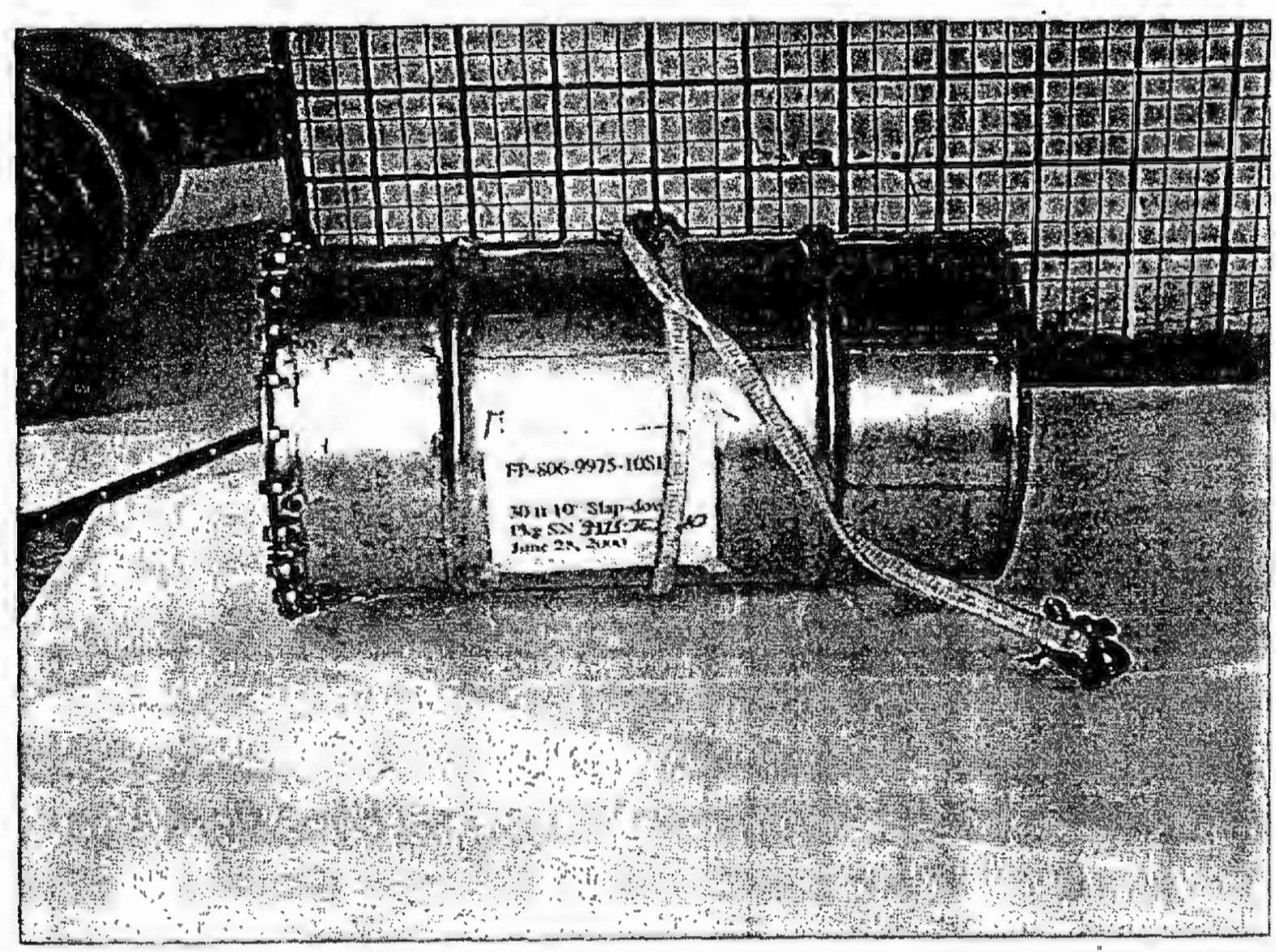

Figure 19. Test 3: 9975-TEST-10 following the NCT preconditioning drop. 
SRTC Radioactive Materials Packaging Technology

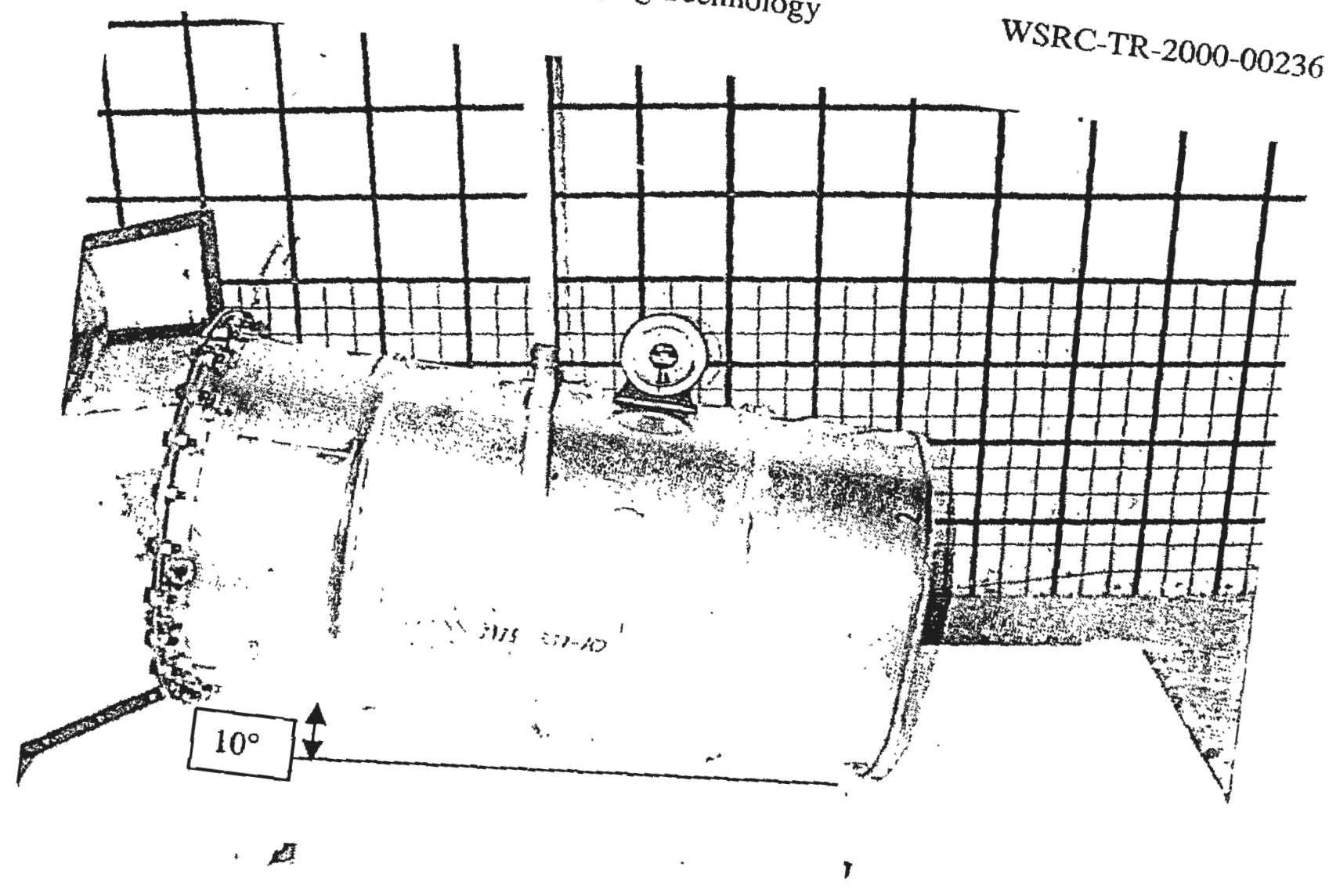

Figure 20. Test 3: 9975-TEst

HAC drop.

TEST-10 rigged for the $10^{\circ}$, bottom down (slap-down) $30 \mathrm{ft}$ 


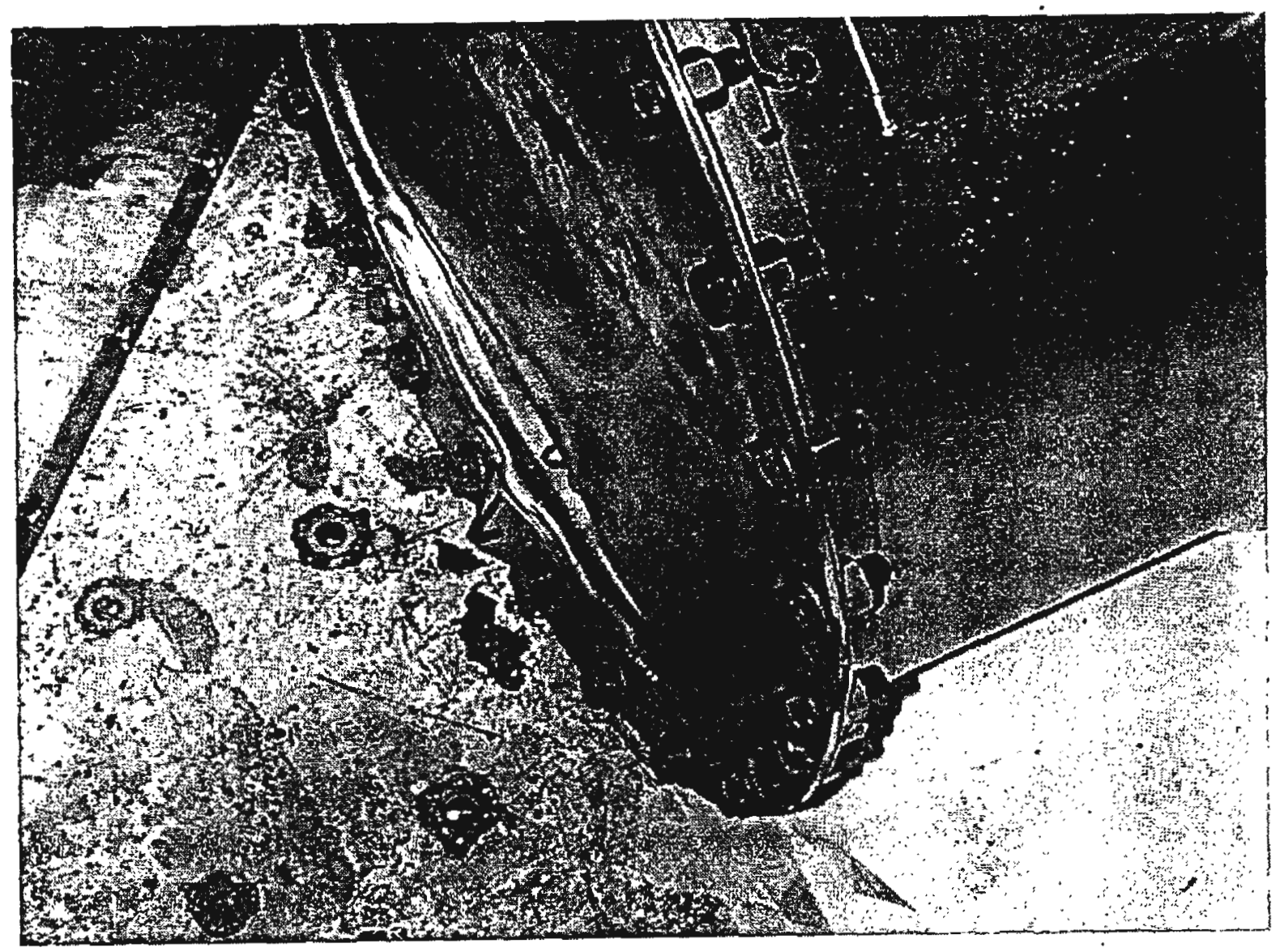

Figure 21. Test 3: View of 9975-TEST-10 following the $30 \mathrm{ft} \mathrm{HAC}$ drop test, showing the buckling of the flange and top. 


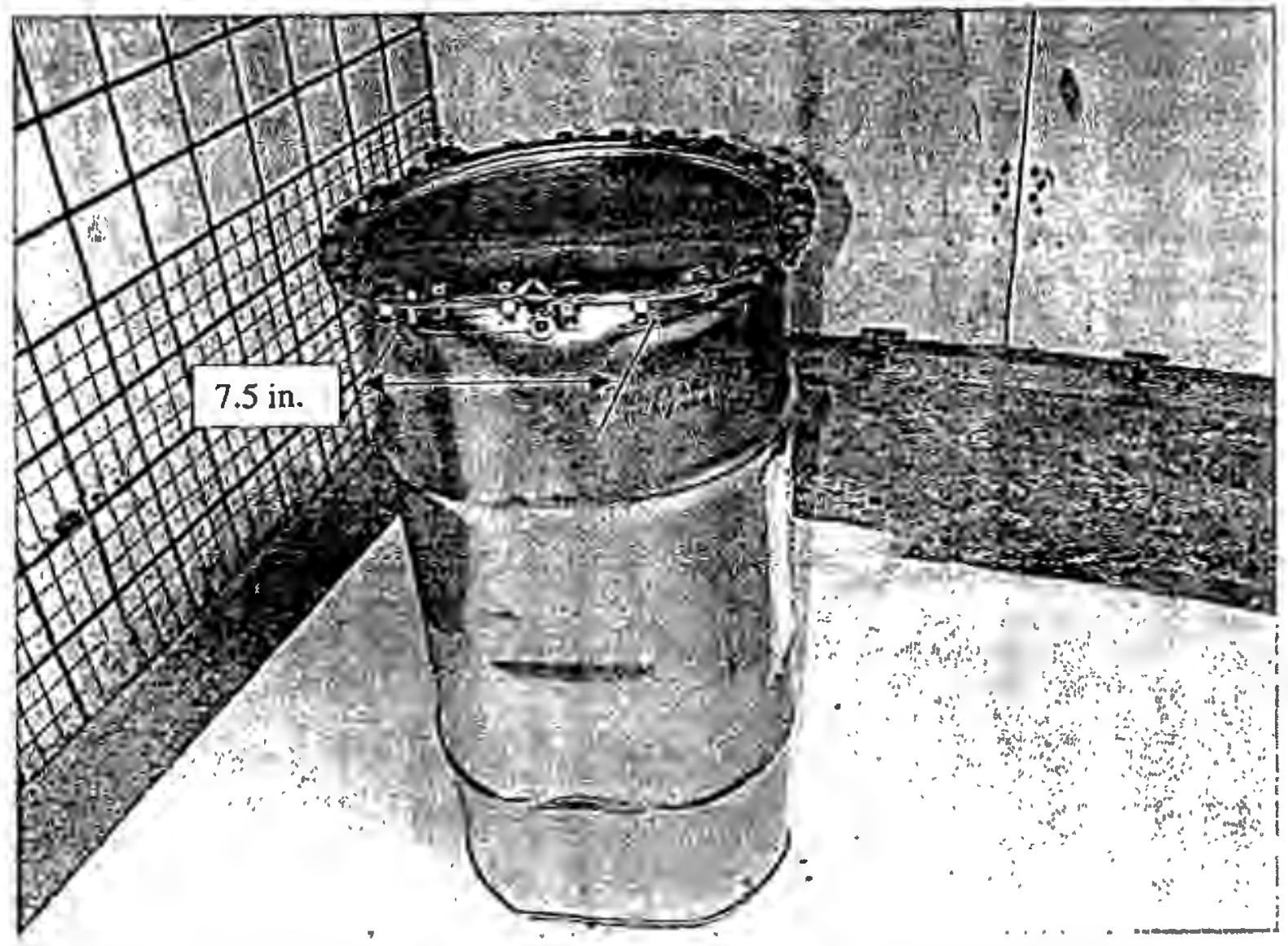

Figure 22. Test 3: Overall view of 9975-TEST-10 following the $30 \mathrm{ft} \mathrm{HAC} \mathrm{drop.}$ 


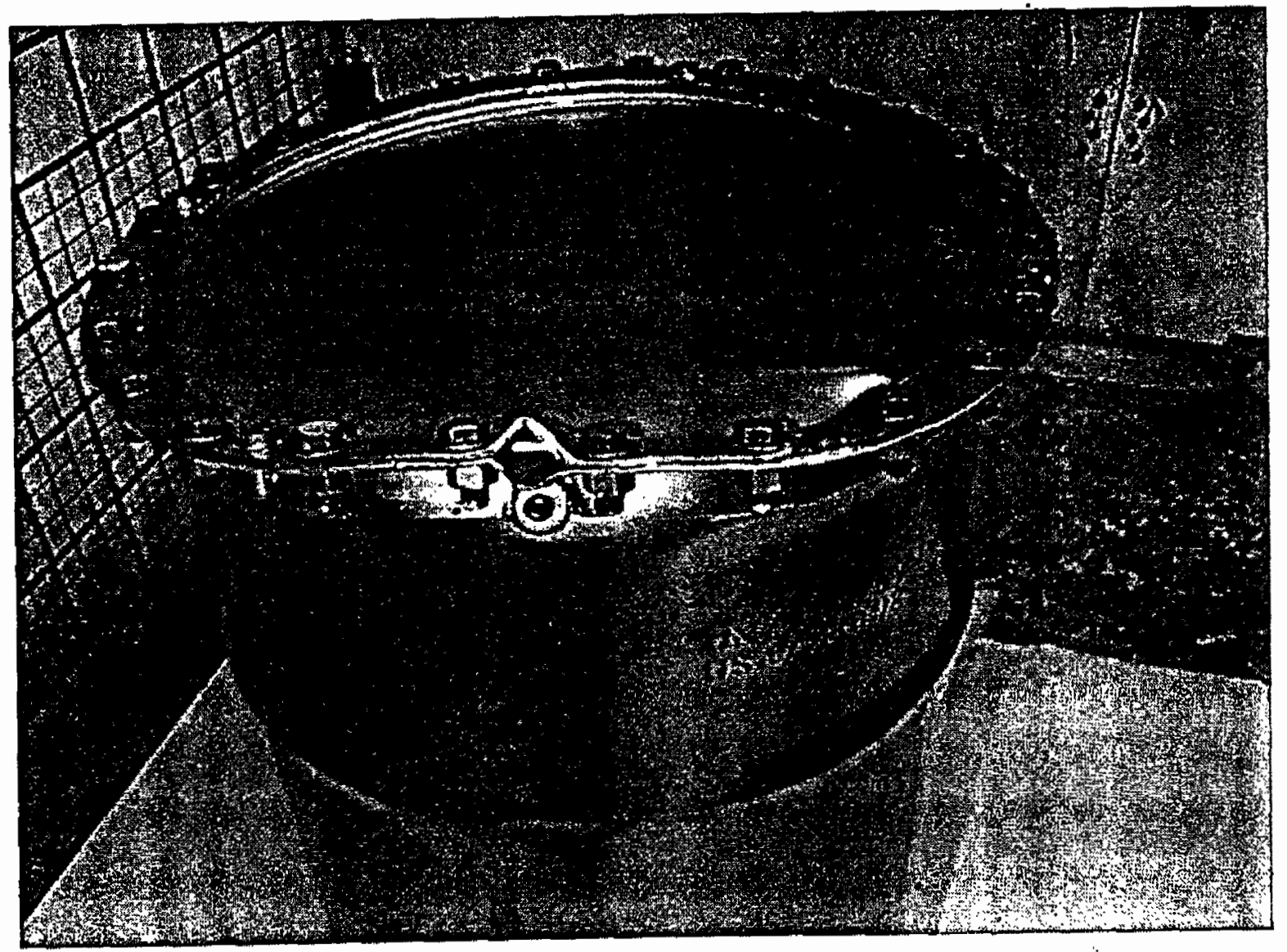

Figure 23. Test 3: Buckled flange assembly and top of 9975-TEST-10 following the $30 \mathrm{ft}$ slap-down drop. 


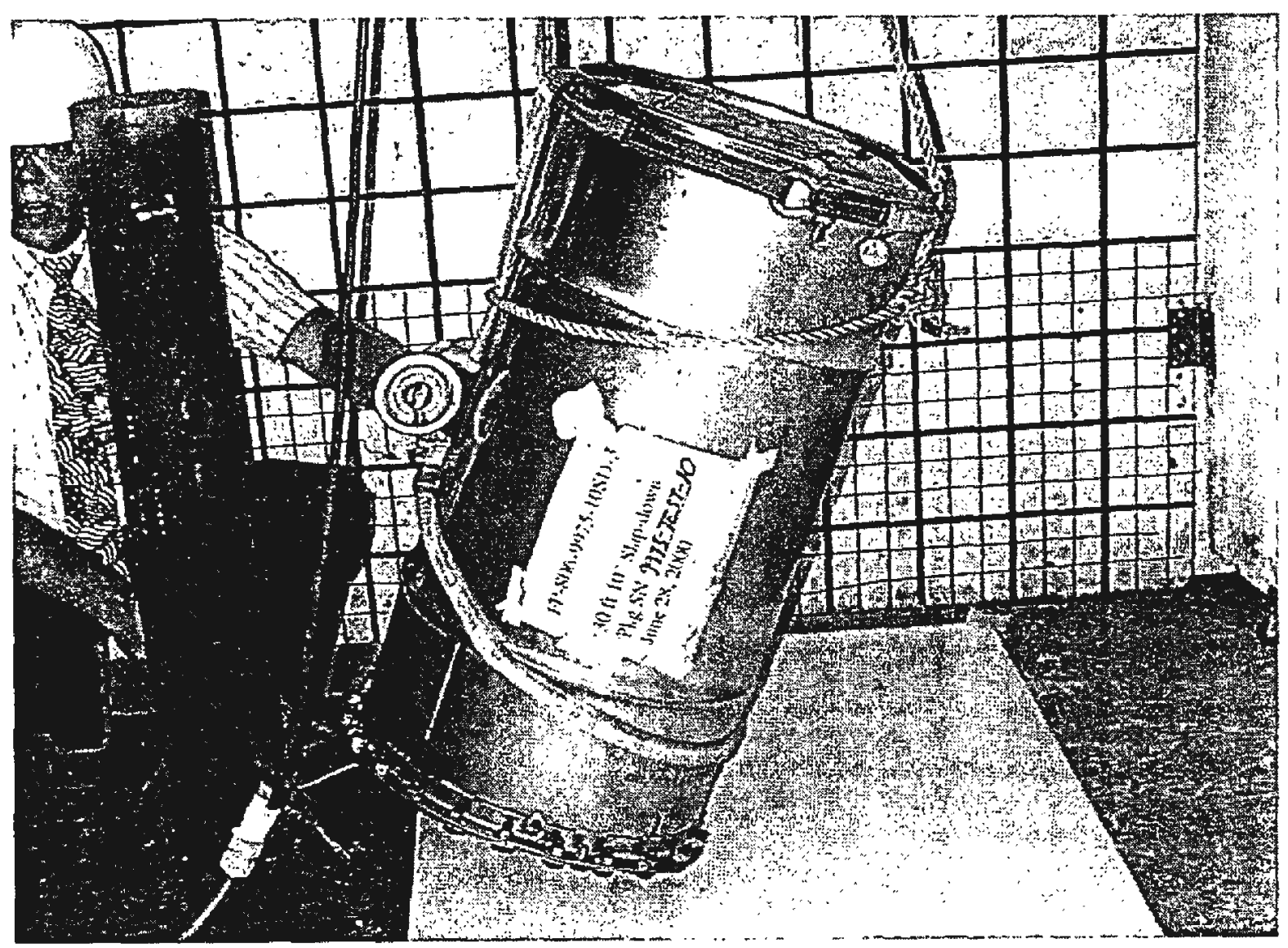

Figure 24. Test 3: Package 9975-TEST-10 rigged for CG-over-impact-point puncture pin test. 


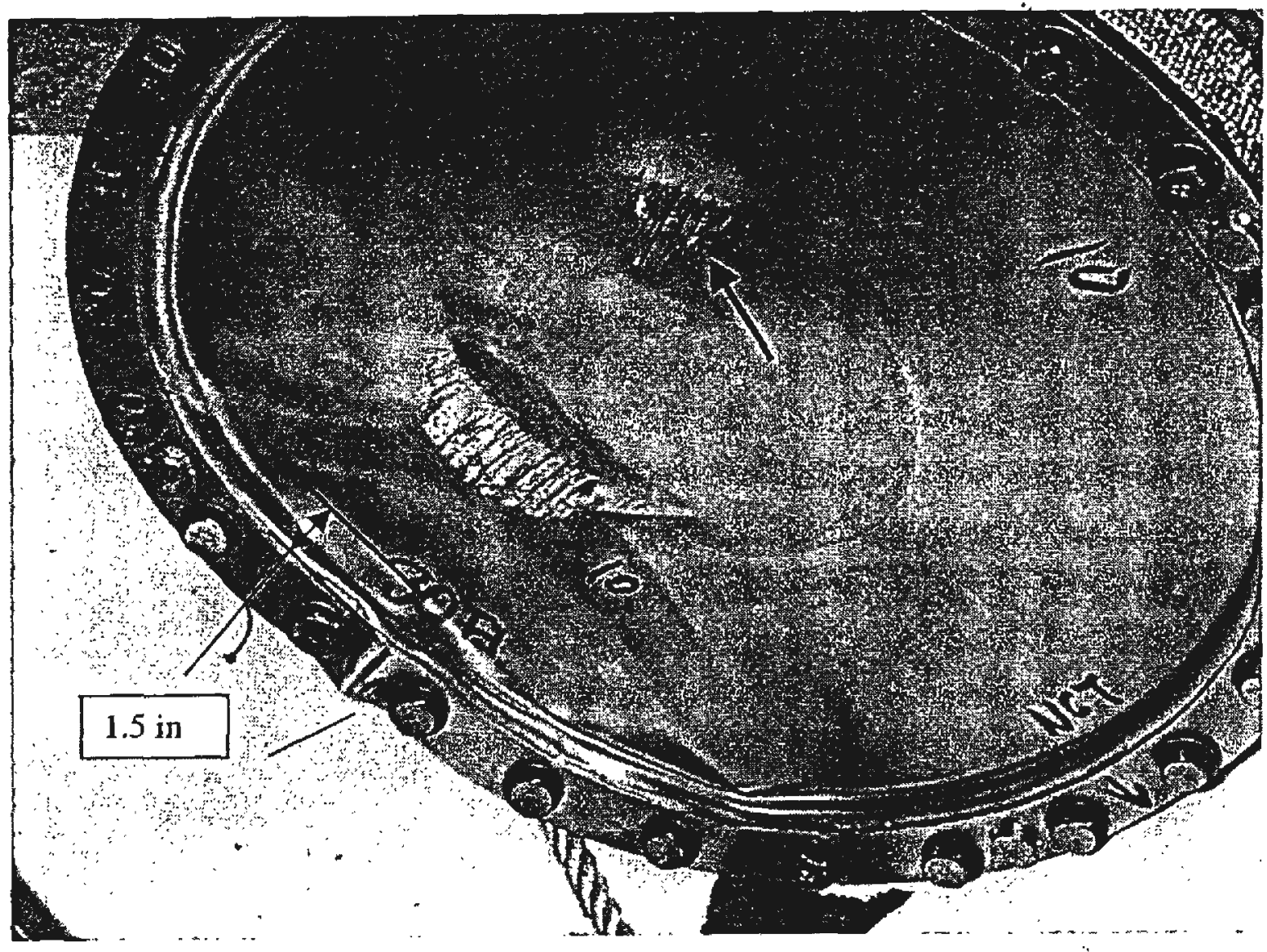

Figure 25. Test 3: Deformation of top of 9975-TEST-10 caused by impact on the puncture pin. The arrow indicates damage caused by the second impact of the package with the pin. The $1.5 \mathrm{in}$. dimension is the distance from the top of the buckled section of the flange ring to the bottom of the buckled section of the package top, measured parallel to the axis of the package. 
Distribution

$\begin{array}{ll}\text { J. S. Bellamy } & 773-54 \mathrm{~A} \\ \text { P. S. Blanton } & 773-53 \mathrm{~A} \\ \text { G. A. Abaramczyk } & 773-54 \mathrm{~A} \\ \text { C. A. McKeel } & 730-1 \mathrm{~B} \\ \text { M.A. Ebra } & 773-42 \mathrm{~A} \\ \text { J. L. England } & 773-54 \mathrm{~A} \\ \text { K. W. Stephens } & 730-4 \mathrm{~B} \\ \text { T. C. Hasty } & 730-4 \mathrm{~B} \\ \text { W. P. Martin } & 730-4 \mathrm{~B} \\ \text { J. H. McAlhaney } & 704-18-\mathrm{F} \\ \text { J. B. Schaade } & 703-\mathrm{F} \\ \text { G. Watts } & 773-54 \mathrm{~A} \\ \text { W.I. Lewis } & 773-43 \mathrm{~A} \\ \text { P. Woodward, File } 22628730-\mathrm{A}\end{array}$

